Supporting Information for

\title{
Mapping the Trimethoprim-Induced Secondary Metabolome of Burkholderia thailandensis
}

\author{
Bethany K. Okada, ${ }^{\dagger, \#}$ Yihan Wu, ${ }^{\dagger, \#}$ Dainan Mao, ${ }^{\dagger}$ Leah B. Bushin, ${ }^{\dagger}$ Mohammad R. \\ Seyedsayamdost ${ }^{\dagger, \ddagger}, *$ \\ Departments of Chemistry ${ }^{\dagger}$ and Molecular Biology ${ }^{\ddagger}$, Princeton University, \\ Princeton, NJ 08544 \\ *email: mrseyed@princeton.edu
}


Materials and strains. All chemicals were obtained from Sigma-Aldrich. Bacterial media and media components were purchased from Becton-Dickinson. Restriction enzymes, Q5 DNA polymerase, and T4 DNA ligase were obtained from New England Biolabs. Plasmid isolation, DNA gel extraction, and PCR purification kits were purchased from Qiagen. Acylhomoserine lactones used in this study $\left(3-\mathrm{OH}-\mathrm{C}_{8}-\mathrm{HSL}\right.$ and $\left.3-\mathrm{OH}-\mathrm{C}_{10}-\mathrm{HSL}\right)$ were kindly provided by Prof. Bonnie Bassler (Princeton University). Burkholderia thailandensis E264, obtained from the American Type Culture Collection, was used throughout this study. A markerless btaQ mutant was generated as described below (see SI Table S14). The btal triple mutant was kindly provided by Prof. Josie Chandler (University of Kansas). ${ }^{1}$ A mutant carrying a transposon insertion in btaK was kindly provided by Prof. Colin Manoil (University of Washington). ${ }^{2}$

Secondary Metabolomic Analysis. B. thailandensis was streaked out onto an LB-agar plate from a frozen cell stock and the plate was incubated at $30^{\circ} \mathrm{C}$ overnight. The plate was used to inoculate $5 \mathrm{~mL}$ of LB-Mops medium (LB $+50 \mathrm{mM}$ Mops, $\mathrm{pH} 7.0$ ) in a $14 \mathrm{~mL}$ bacterial culture tube, which was incubated at $30^{\circ} \mathrm{C}$ and $250 \mathrm{rpm}$ overnight. After 16 hours, the overnight culture was used to inoculate six $125 \mathrm{~mL}$ Erlenmeyer flasks, each containing $20 \mathrm{~mL}$ LB-Mops, at an initial $\mathrm{OD}_{600 \mathrm{~nm}}$ of 0.05 . Three flasks were supplemented with $50 \mu \mathrm{L}$ DMSO (control), while the other three were supplemented with $50 \mu \mathrm{L}$ of a $12 \mathrm{mM}$ trimethoprim stock (prepared in DMSO) to give a final concentration of $30 \mu \mathrm{M}$. The cultures were grown at $30^{\circ} \mathrm{C}$ and $250 \mathrm{rpm}$ for $28 \mathrm{~h}$, at which point they were extracted with $20 \mathrm{~mL}$ of ethyl acetate. The organic layer was isolated with a separatory funnel, dried over $\mathrm{Na}_{2} \mathrm{SO}_{4}$, and then dried completely in vacuo.

Each sample was dissolved in $600 \mu \mathrm{L} \mathrm{MeOH}$, filtered, and analyzed on an Agilent UHD Accurate Mass Q-tof LC-MS system, equipped with a 1260 Infiinty series HPLC, a JetStream ESI source, and the 6540 Q-tof. The six samples were analyzed in a randomized fashion, preceded by three wash runs (MeOH injection). The samples were resolved on an Agilent Poroshell 120 EC-C18 column $(3 \times 50 \mathrm{~mm}, 2.7 \mu \mathrm{m})$ at $0.4 \mathrm{~mL} / \mathrm{min}$ using water + formic acid $(0.1 \%)$ and $\mathrm{MeCN}+$ formic acid $(0.1 \%)$ as the mobile phase. After injection, elution was carried out isocratically for $3 \mathrm{~min}$ at 15\% MeCN, followed by a gradient from 15-95\% MeCN over 18 min, followed by a $3 \mathrm{~min}$ hold at $95 \% \mathrm{MeCN}$. Nebulizer pressure, sheath gas temperature, and fragmentor voltage were set to $20 \mathrm{psi}, 390 \mathrm{C}$, and $180 \mathrm{~V}$, respectively. Data were collected from $100-1700 \mathrm{~m} / \mathrm{z}$ in positive ion detection mode.

Agilent's Mass Profiler Professional and ProFinder were used to analyze the data. Molecular feature extraction was carried out using the 'common organic molecule' model and a 300 count minimum peak height threshold. A minimum ion count threshold of 2 was applied, and only ions present in all three replicates were included in the analysis. Each molecular 
feature was integrated using an 'Agile' function. This analysis afforded features that are unique to the control sample, the Tmp treatment, or present in both.

MS/MS Network Analysis. B. thailandensis was cultured in LB-Mops as described above. After $28 \mathrm{~h}$, the supernatant was collected and three separate extraction methods were applied to the control and the Tmp-treated samples: (1) a 1:1 ethyl acetate extraction, as described above, (2) solid-phase extraction with a C18 Seppak resin (Phenomenex, $100 \mathrm{mg}$ ), and (3) solid-phase extraction with a Hypercarb Hypersil resin (ThermoFisher, $100 \mathrm{mg}$ ). In case of solid-phase extraction, the columns were first washed with $10 \mathrm{CV}$ of $\mathrm{MeCN}$, then equilibrated with $10 \mathrm{CV}$ water. Upon loading, elution was carried out with $5 \mathrm{CV}$ of $20 \% \mathrm{MeCN}, 50 \% \mathrm{MeCN}$, and $100 \%$ $\mathrm{MeCN}$. Fractions obtained from the various extraction procedures were dried in vacuo, resuspended in $\mathrm{MeOH}$, and analyzed on an Agilent UHD Accurate Mass Q-tof LC-MS system, as detailed above. The LC method and column described above were also used for this experiment. MS/MS data were collected under positive ion detection mode using variable collision energies between $20-100 \mathrm{~V}$, a scan rate of 4 spectra per second, and a spectral range of $100-1700 \mathrm{~m} / \mathrm{z}$. The MS/MS data of all extracts (control and Tmp) were clustered as described by Watrous et al. ${ }^{3}$ Briefly, clustering was carried out with a precursor mass tolerance of $2.0 \mathrm{Da}$, a fragment mass tolerance of $0.5 \mathrm{Da}$, the cosine threshold set at 0.5 , and the minimum matched peaks set at 6 . The data from the various extraction methods were combined and grouped by treatment (control vs. Tmp). Redundant nodes resulting from $\mathrm{Na}^{+}$salts of certain metabolites were removed. The results were visualized in Cytoscape with the FM3 layout.

Purification of Capistruin B and C. B. thailandensis was cultured in BT medium (per L: 15 g glucose, $10 \mathrm{~g}$ yeast extract, $10 \mathrm{~g} \mathrm{CaCO}_{3}, \mathrm{pH}=6.5$ ) supplemented with trimethoprim at a final concentration of $30 \mu \mathrm{M}$ at $30^{\circ} \mathrm{C}$ and $200 \mathrm{rpm}$. After $28 \mathrm{~h}$, the supernatant was collected and loaded onto a C18 Seppak resin (Phenomenex, $2 \mathrm{~g}$ ), which had been equilibrated with water. The resin was washed with $5 \mathrm{CV}$ of water, then eluted with $10 \mathrm{CV}$ of each $20 \% \mathrm{MeCN}, 50 \%$ $\mathrm{MeCN}$, and $100 \% \mathrm{MeCN}$. The $50 \%$ fraction contained the desired capistruins, as assessed by HPLC-MS. This fraction was dried in vacuo, resuspended in $1: 1 \mathrm{MeOH} / \mathrm{H}_{2} \mathrm{O}$, and further purified by preparative HPLC using a Phenomenex Luna C18 column $(21.2 \times 250 \mathrm{~mm}, 5 \mu \mathrm{m})$ operating at a flow rate of $12 \mathrm{~mL} / \mathrm{min}$ with a gradient of $30-100 \% \mathrm{MeCN}$ (in $\mathrm{H}_{2} \mathrm{O}$ ) over $30 \mathrm{~min}$. Fractions containing capistruins, as judged by HPLC-MS, were pooled and resolved by semi-preparative HPLC on a Supelco Discovery RP Amide C16 column (10 x $250 \mathrm{~mm}, 5 \mu \mathrm{m})$ operating at 2.5 $\mathrm{mL} / \mathrm{min}$ with an elution gradient of $10-100 \% \mathrm{MeCN}$ (in $\mathrm{H}_{2} \mathrm{O}$ ) over 23 min. Capistruin $\mathrm{B}$ was purified to homogeneity on a Phenomenex Luna C18 column $(4.6 \times 150 \mathrm{~mm}, 5 \mu \mathrm{m})$ at $1 \mathrm{~mL} / \mathrm{min}$ and an elution gradient of $20-30 \% \mathrm{MeCN}$ (in $\mathrm{H}_{2} \mathrm{O}$ ) over 30 min. Capistruin $\mathrm{C}$ was purified to 
homogeneity on the same column with the same flow rate and a gradient of $15-30 \% \mathrm{MeCN}$ (in $\mathrm{H}_{2} \mathrm{O}$ ) over 30 min. All solvents used for HPLC purifications contained $0.1 \%(\mathrm{v} / \mathrm{v})$ formic acid.

Structure calculations. For each capistruin analog, a NOESY spectrum acquired in $\mathrm{H}_{2} \mathrm{O} / \mathrm{D}_{2} \mathrm{O}(9: 1)$ at $283 \mathrm{~K}$ with a mixing time of $300 \mathrm{~ms}$ exhibited the greatest number of correlations, while avoiding spin diffusion, and was therefore used for structure calculations. Cross-peak positions and volumes in this spectrum were measured in CcpNMR Analysis Software and assigned manually. These were given as initial input data for the calculations, which were performed in CYANA 2.1 on a Linux cluster. ${ }^{4}$ The isopeptide bond was incorporated via explicit distance constraints for the $\mathrm{N}-\mathrm{C}$ bond between the $\mathrm{N}$ of Gly1 and the $\mathrm{CY}$ of Asp9. Specifically, the upper and lower limits for the N-Cy bond length were set to $1.6 \AA$ and $1.4 \AA$, respectively, with weighting factors of 1.00 . These distances were based on the average bond length of an amide bond. Seven cycles of combined NOESY assignment and structure calculation were performed followed by a final structure calculation. Calibration parameters for extraction of distance constraints from cross-peak volumes were determined automatically. For each cycle and for the final calculation, 100 initial conformers were generated and a simulated annealing schedule, composed of 10,000 torsion angle dynamic steps, was applied to each conformer. Statistics were generated for the 10 conformers with the lowest final target functions (see Table S5). The calculated conformers were visualized in PyMoL.

Structural elucidation, Marfey's, and Mosher ester analyses. The structures of acybolins A-E were elucidated using ${ }^{1} \mathrm{H},{ }^{13} \mathrm{C}$, gCOSY, TOCSY, gHSQC (with a ${ }^{13} \mathrm{C}$ adiabatic inversion pulse), and gHMBC spectra, along with HR-MS and tandem HR-MS data. Marfey's analysis to determine the stereochemistry of the Ala groups in acybolin A was carried out as previously outlined. ${ }^{5,6}$ Briefly, $0.2 \mathrm{mg}$ of acybolin A was dissolved in $1 \mathrm{~mL}$ of $6 \mathrm{~N} \mathrm{HCl}$ in a $4 \mathrm{~mL}$ scintillation vial and heated in an oil bath for $1.5 \mathrm{~h}$ at $115^{\circ} \mathrm{C}$. $\mathrm{HCl}$ was removed in vacuo and the material redissolved in $1 \mathrm{~mL}$ water. This process was repeated twice to completely remove the residual acid. The sample was then loaded onto a PrepSep C8 cartridge (Fisher Scientific) and Ala was eluted with $10 \% \mathrm{MeCN}$ in $\mathrm{H}_{2} \mathrm{O}$. The eluent was subjected to Marfey's analysis as previously described in detail (see Fig. S12). ${ }^{5}$ Mosher ester analysis was carried out as previously described using $200 \mu \mathrm{g}$ of acybolin A (see Fig. S13). ${ }^{7}$

Generation of $\Delta b t a Q$ deletion mutant. B. thailandensis E264 genomic DNA was isolated using the Promega Wizard gDNA purification kit. Approximately, one kb regions upstream and downstream of btal2 were amplified from the gDNA using primers \#1-4 (Table S14) and a proofreading DNA polymerase. Overlap PCR allowed fusion of these homologous regions to the trimethopim resistance marker. This cassette was digested with HindIII and Kpnl and ligated 
into pEX18Kan-PheS ${ }^{8}$ using T4 DNA ligase. The resulting KO plasmid (pBTHII_1227KO) was amplified in E. coli $\mathrm{DH} 5 \alpha$ cells, purified, and introduced into B. thailandensis E264 by conjugative transfer via filter mating using $E$. coli donor $\mathrm{JV} 36 .{ }^{9}$ Briefly, LB cultures of both the $E$. coli donor and $B$. thailandensis were grown to an $\mathrm{OD}_{600 \mathrm{~nm}}$ of 0.5 . Fifty $\mu \mathrm{L}$ of each culture was mixed into $10 \mathrm{~mL} L B$ and the mixture filtered through a sterile filter membrane. The membrane was carefully removed, placed on a pre-warmed LB agar plate, and incubated at $30^{\circ} \mathrm{C}$ for $8-10$ $\mathrm{h}$. The cells were then washed off by vortexing the membrane in a $50 \mathrm{~mL}$ falcon tube containing $5 \mathrm{~mL}$ LB. Approximately $50 \mu \mathrm{L}$ of this mixture were plated onto LB agar containing $100 \mu \mathrm{g} / \mathrm{mL}$ of both streptomycin and trimethoprim. After incubation at $30^{\circ} \mathrm{C}$, individual colonies were subjected to second round of selection on the same plate. Surviving colonies were recovered in $2 \mathrm{~mL} L B$ overnight and plated onto M9 minimal agar supplemented with $0.2 \%$ p-chloro-Phenylalanine. The desired markerless mutant was obtained after incubation at $30^{\circ} \mathrm{C}$. These were verified PCR using primers flanking the recombination sites (Table S14) and by DNA sequencing.

Acybolin production by $B$. thailandensis mutants $\Delta b t a Q, \Delta b t a l 1-/ 3$ (triple mutant), btaK::Tn, and BTHI2757::Tn. Colonies from each mutant grown on an LB agar plate were used to inoculate $5 \mathrm{~mL}$ of LB-Mops in a $14 \mathrm{~mL}$ sterile culture tube. These were grown overnight, diluted to a final $\mathrm{OD}_{600 \mathrm{~nm}}$ of 0.05 in $20 \mathrm{~mL}$ of LB-Mops containing $30 \mu \mathrm{M}$ trimethoprim (in a 125 $\mathrm{mL}$ Erlenmeyer Flask), and cultured at $30^{\circ} \mathrm{C}$ and $250 \mathrm{rpm}$ for $28 \mathrm{~h}$. The cultures were extracted with one volume of EtOAc, dried over $\mathrm{Na}_{2} \mathrm{SO}_{4}$, and further dried to completeness in vacuo. The dried extract from each culture was redissolved in $\mathrm{MeOH}$ and analyzed by HPLC-MS as described above (see Figures 4 and S14). In the case of the triple $\Delta b t a l$ mutant, the small culture was prepared as described for the other mutants. After overnight growth at $30^{\circ} \mathrm{C}$ and $250 \mathrm{rpm}, 4 \times 125 \mathrm{~mL}$ Erlenmeyer flasks, each containing $20 \mathrm{~mL}$ LB+Mops, were inoculated to an initial $\mathrm{OD}_{600 \mathrm{~nm}}$ of 0.05 . One flask was supplemented with $30 \mu \mathrm{M}$ trimethoprim, the second with 4 $\mu \mathrm{M} 3-\mathrm{OH}-\mathrm{C}_{10}-\mathrm{HSL}$ and $30 \mu \mathrm{M}$ trimethoprim, the third with $2 \mu \mathrm{M} 3-\mathrm{OH}-\mathrm{C}_{10}-\mathrm{HSL}$ and $30 \mu \mathrm{M}$ trimethoprim, and the fourth with $4 \mu \mathrm{M} 3-\mathrm{OH}-\mathrm{C}_{10}-\mathrm{HSL}, 2 \mu \mathrm{M} 3-\mathrm{OH}-\mathrm{C}_{8}-\mathrm{HSL}$, and $30 \mu \mathrm{M}$ trimethoprim. The AHL concentrations were chosen according to Majerczyk et al. ${ }^{10}$ After growth at $30^{\circ} \mathrm{C}$ and $250 \mathrm{rpm}$ for $26 \mathrm{~h}$, acybolin was assessed by HPLC-MS. Experiments were also

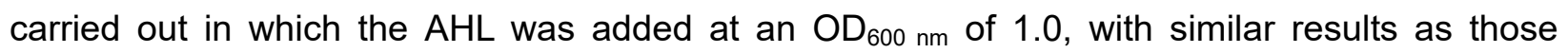
shown in Fig. 4. 

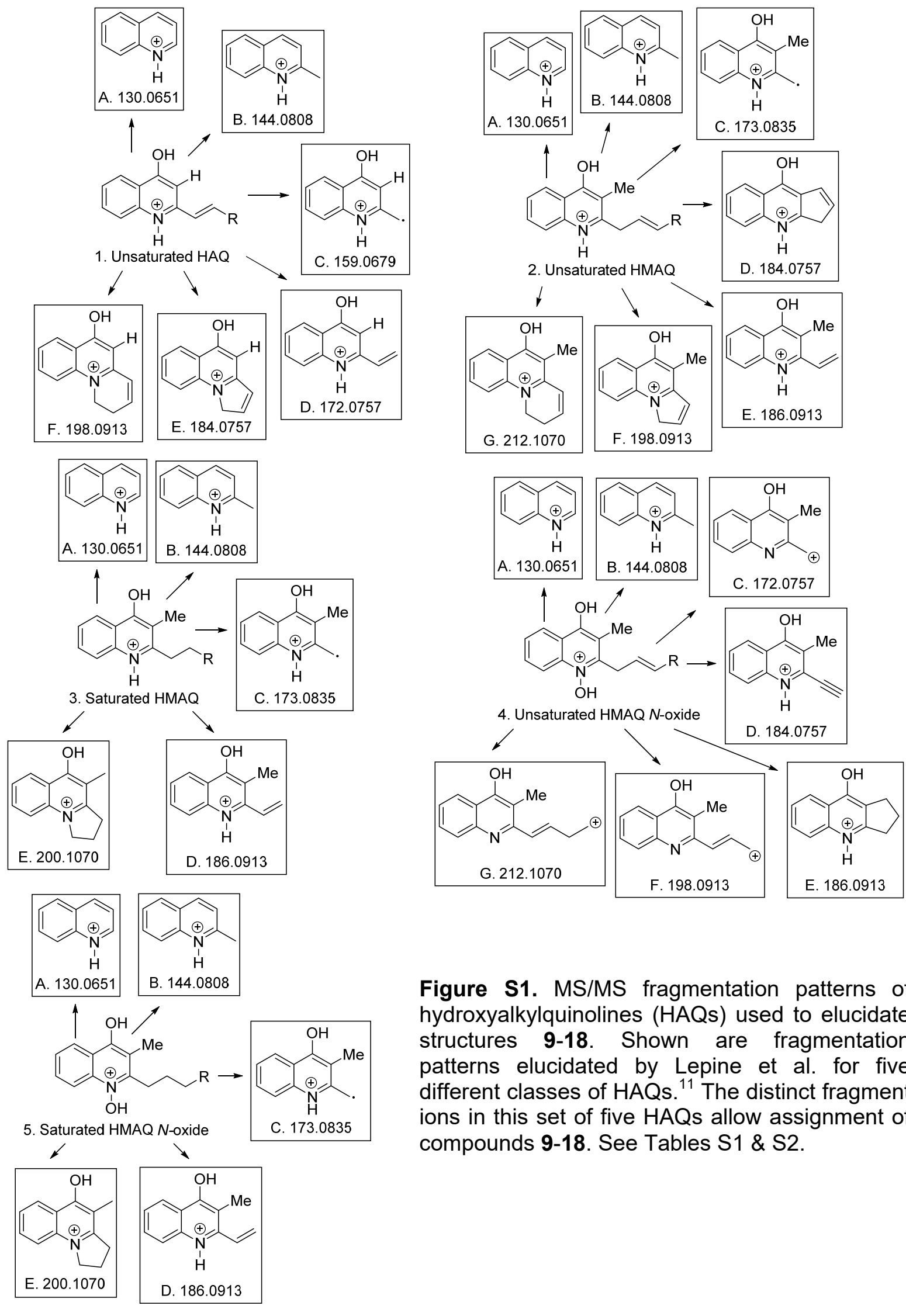

Figure S1. MS/MS fragmentation patterns of hydroxyalkylquinolines (HAQs) used to elucidate structures 9-18. Shown are fragmentation patterns elucidated by Lepine et al. for five different classes of HAQs. ${ }^{11}$ The distinct fragment ions in this set of five HAQs allow assignment of compounds 9-18. See Tables S1 \& S2. 
<smiles>COC(/C(C)=C/C=C\C=C(C)\C=C\CC(O)CC(=O)/C=C/C=C(C)/C=C/C(C)NC(=O)C(C)C/C=C/CC(O)Cc1ccc(O)cc1)C(C)C(=O)O</smiles><smiles>C[C@H](N)C(=O)N[C@@H](C)C(=O)N[C@@H]1[C@@H]2CC(O)CC(O)=C2C(=O)O[C@H]1C(Cl)Cl</smiles>

Bactobolin B (23)<smiles>CC(N)C(=O)N[C@@H](C)C(=O)N[C@@H](C)C(=O)NC1C2C(=C(O)CC(O)C2O)C(=O)O[C@H]1C(Cl)Cl</smiles><smiles>CC(N)C(=O)N[C@H]1C2CC(O)CC(O)=C2C(=O)O[C@H]1C(Cl)Cl</smiles>

Bactobolin C (24)<smiles>C[C@H](N)C(=O)N[C@@H](C)C(=O)N[C@H]1C2CC(O)CC(O)=C2C(=O)O[C@H]1C(Cl)Cl</smiles>

Bactobolin D (25)

Figure S2. Secondary metabolites identified in the MS/MS network, which are not shown in Fig. 2. Note that thailandamide $C(21)$ represents a new thailandamide analog, while those of bactobolin, malleilactone, and burkholdac have been described before (23-28). See Table S1. 

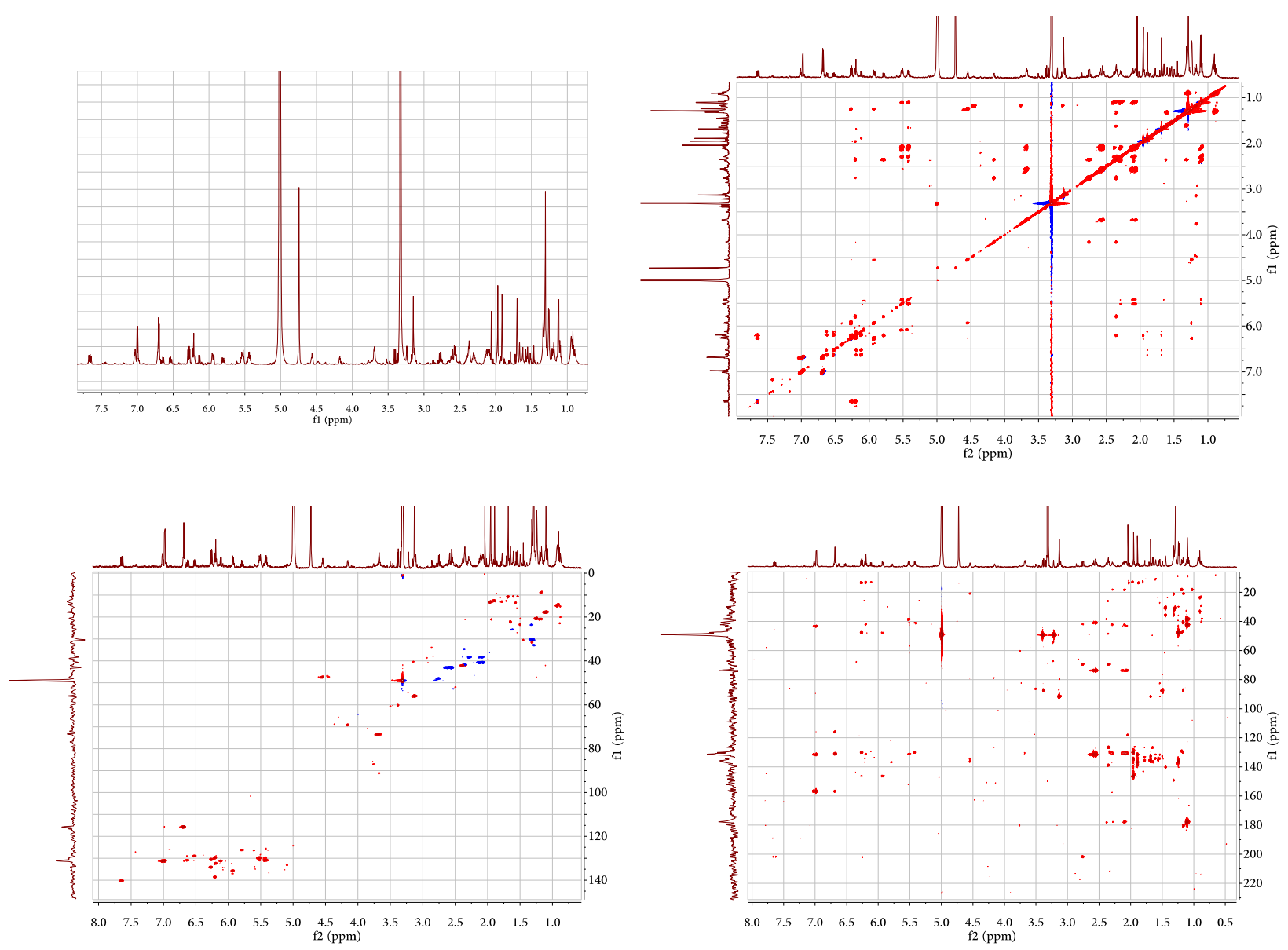

Figure S3. NMR data for thailandamide $\mathrm{C}$ in $\mathrm{MeOH}-d 4:{ }^{1} \mathrm{H}$ spectrum (top left), TOCSY (top right), DEPT-edited gHSQC (bottom left), and HMBC (bottom right). 


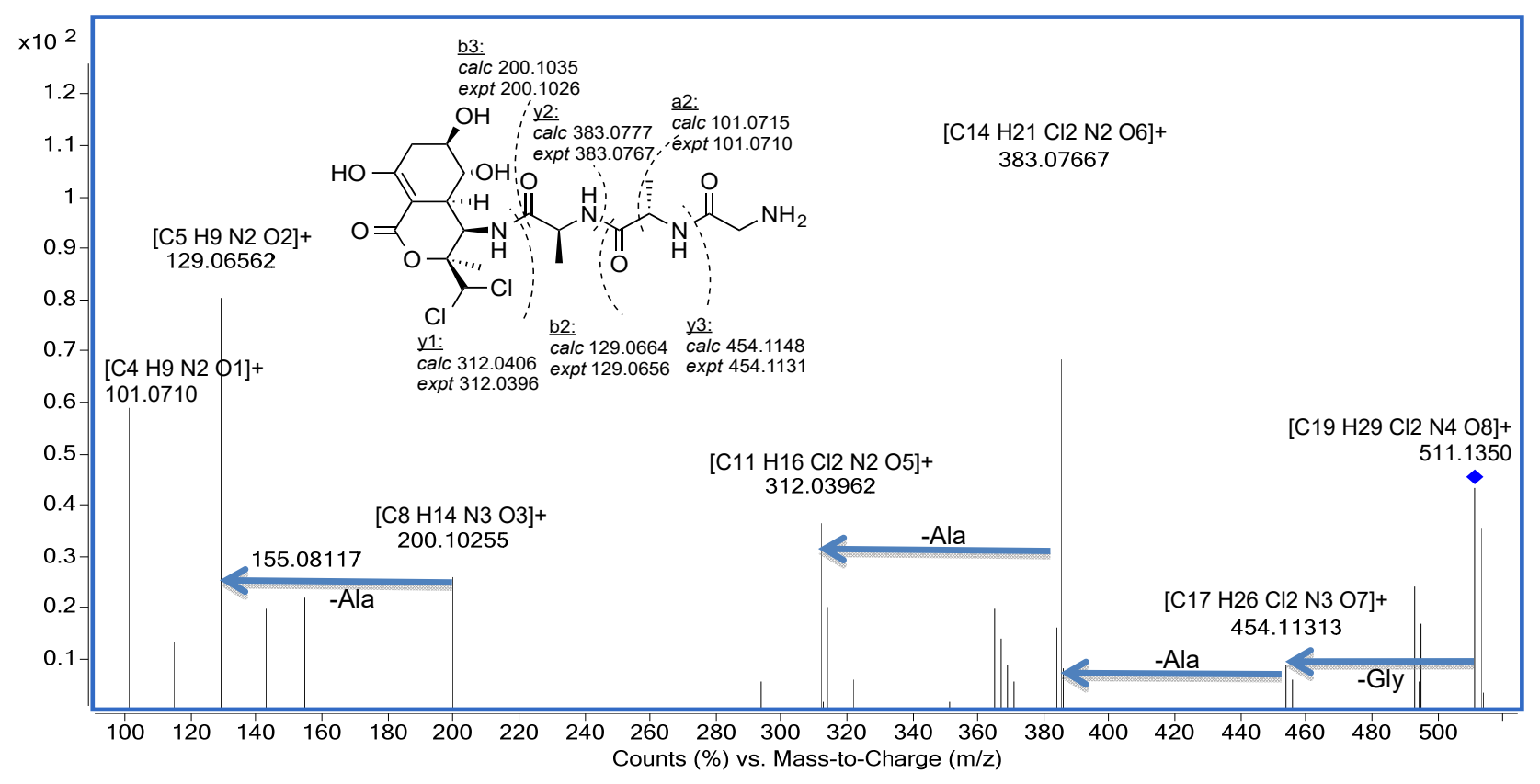

Figure S4. Tandem HR-MS analysis of bactobolin I. Calculated and expected $\mathrm{m} / \mathrm{z}$ for the $\mathrm{N}$ acylated b2 and b3 ions, the $C$-terminally-modified y1, y2, and y3 ions, as well as an a2 ion are shown. See Table S13. 


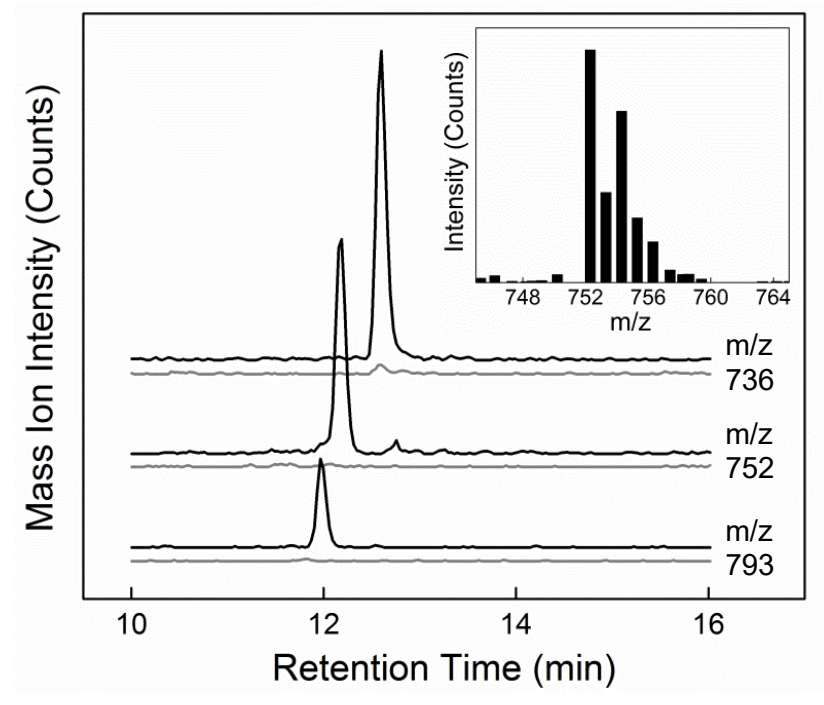

Figure S5. Detection of acybolins in trimethoprim-induced cultures of $B$. thailandensis. Black and gray traces correspond to cultures containing $30 \mu \mathrm{M}$ trimethoprim or no inducer, respectively. Shown are mass ion extractions for acybolin $A(\mathrm{~m} / \mathrm{z} 736$, top), acybolin $B$ ( $\mathrm{m} / \mathrm{z} 752$, middle), and acybolin $\mathrm{C}$ ( $\mathrm{m} / \mathrm{z} 793$, bottom). Inset, mass spectrum of acybolin B displaying an isotopic distribution typical for dichlorinated compounds. 


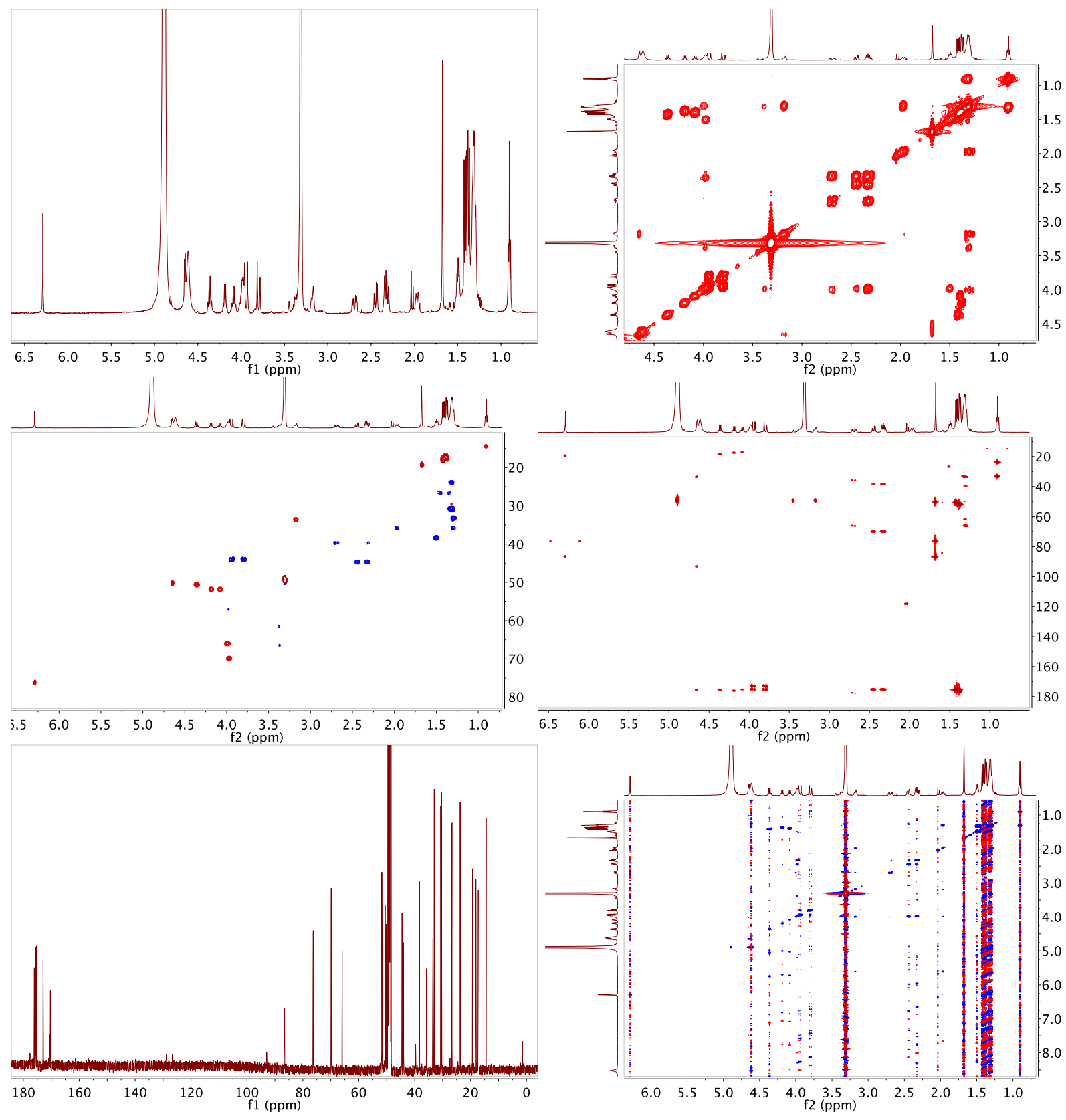

Figure S6. NMR of acybolin A in $\mathrm{MeOH}-d_{4}:{ }^{1} \mathrm{H}$ spectrum (top left), gCOSY (top right), gHSQC, DEPT-edited (middle left), HMBC (middle right), ${ }^{13} \mathrm{C}$ spectrum (bottom left), TOCSY (bottom right). 


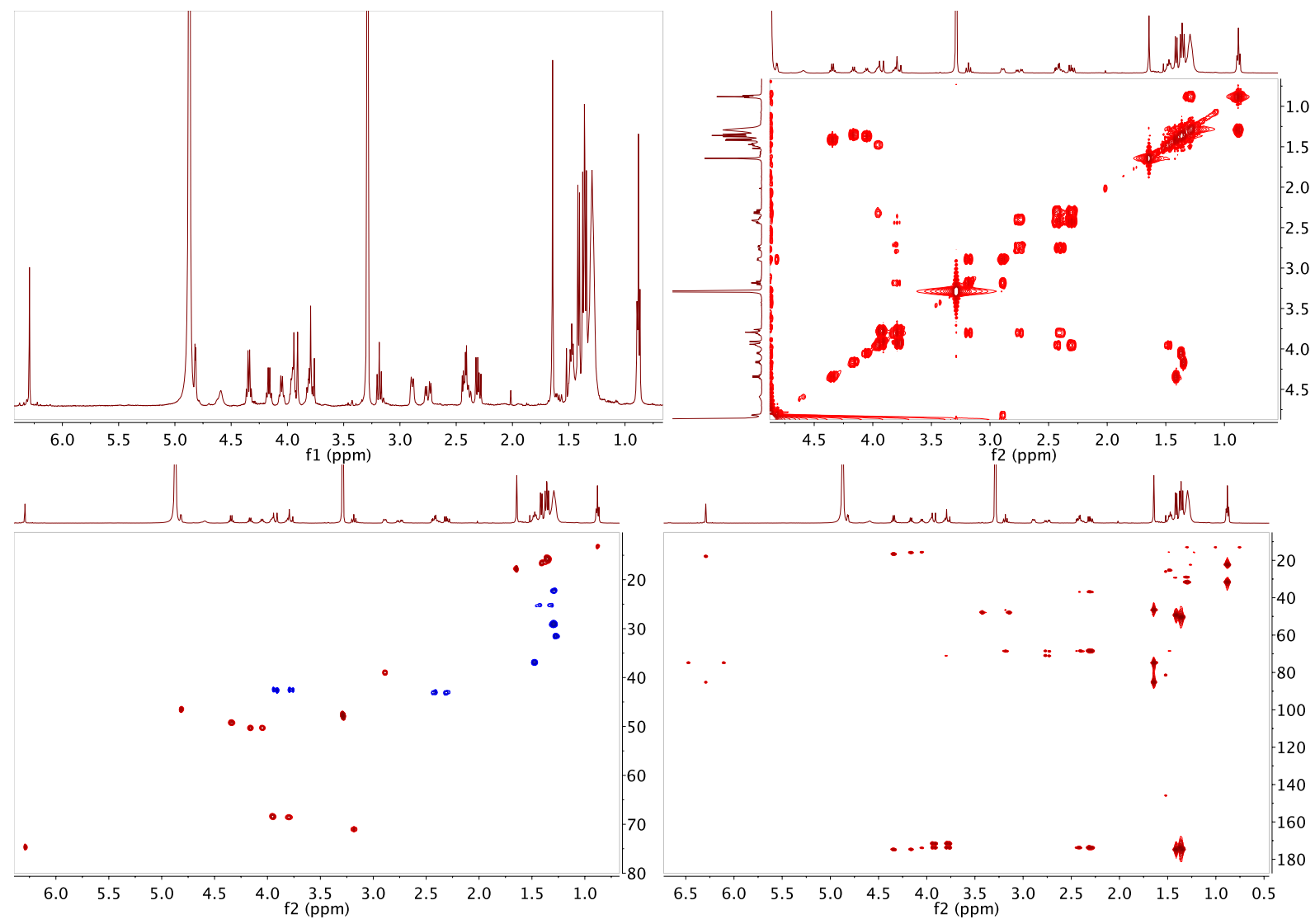

Figure S7. NMR of acybolin B in $\mathrm{MeOH}-d_{4}:{ }^{1} \mathrm{H}$ spectrum (top left), gCOSY (top right), gHSQC, DEPT-edited (bottom left), HMBC (bottom right). 


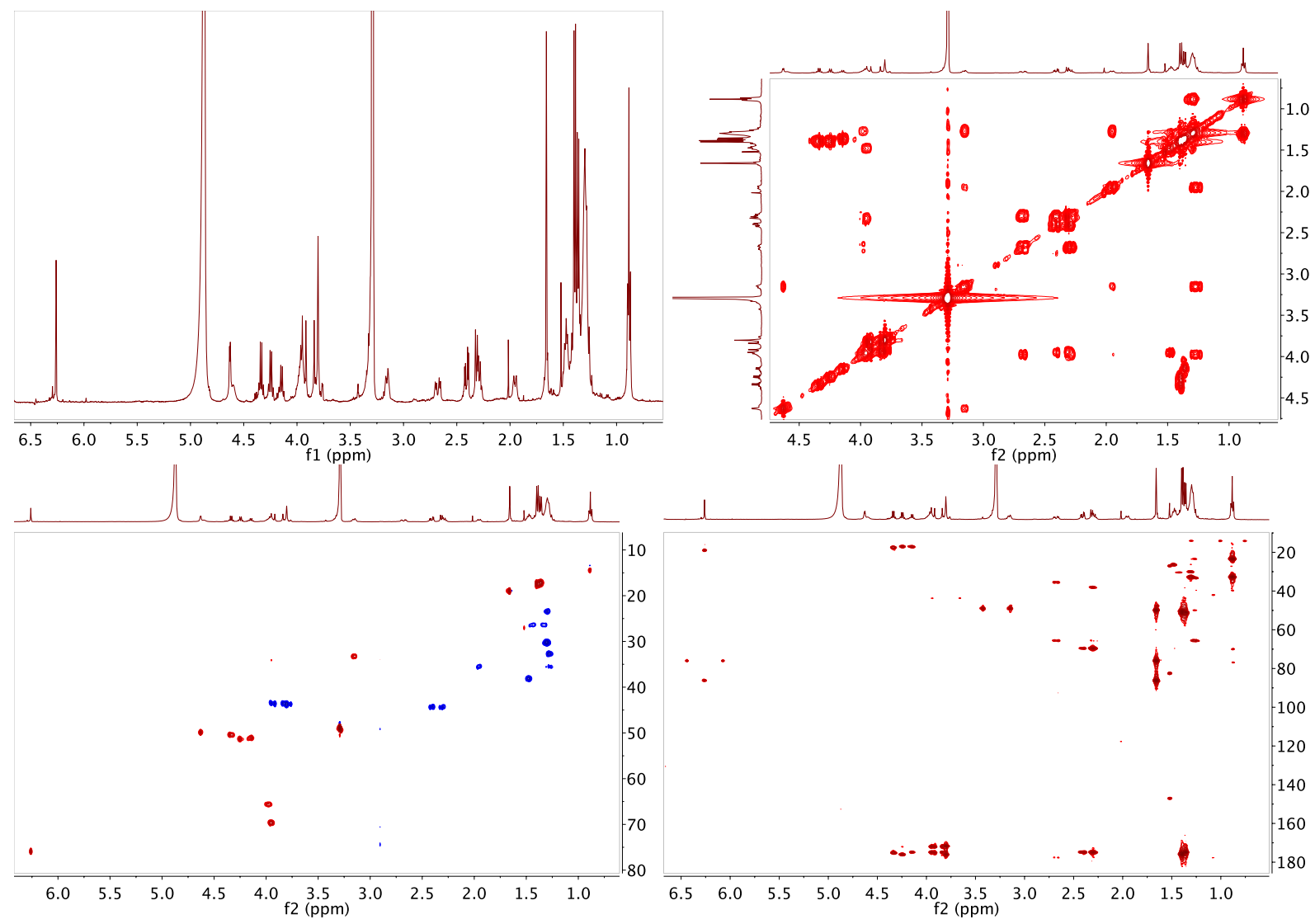

Figure S8. NMR of acybolin $\mathrm{C}$ in $\mathrm{MeOH}-d_{4}:{ }^{1} \mathrm{H}$ spectrum (top left), gCOSY (top right), gHSQC, DEPT-edited (bottom left), HMBC (bottom right). 


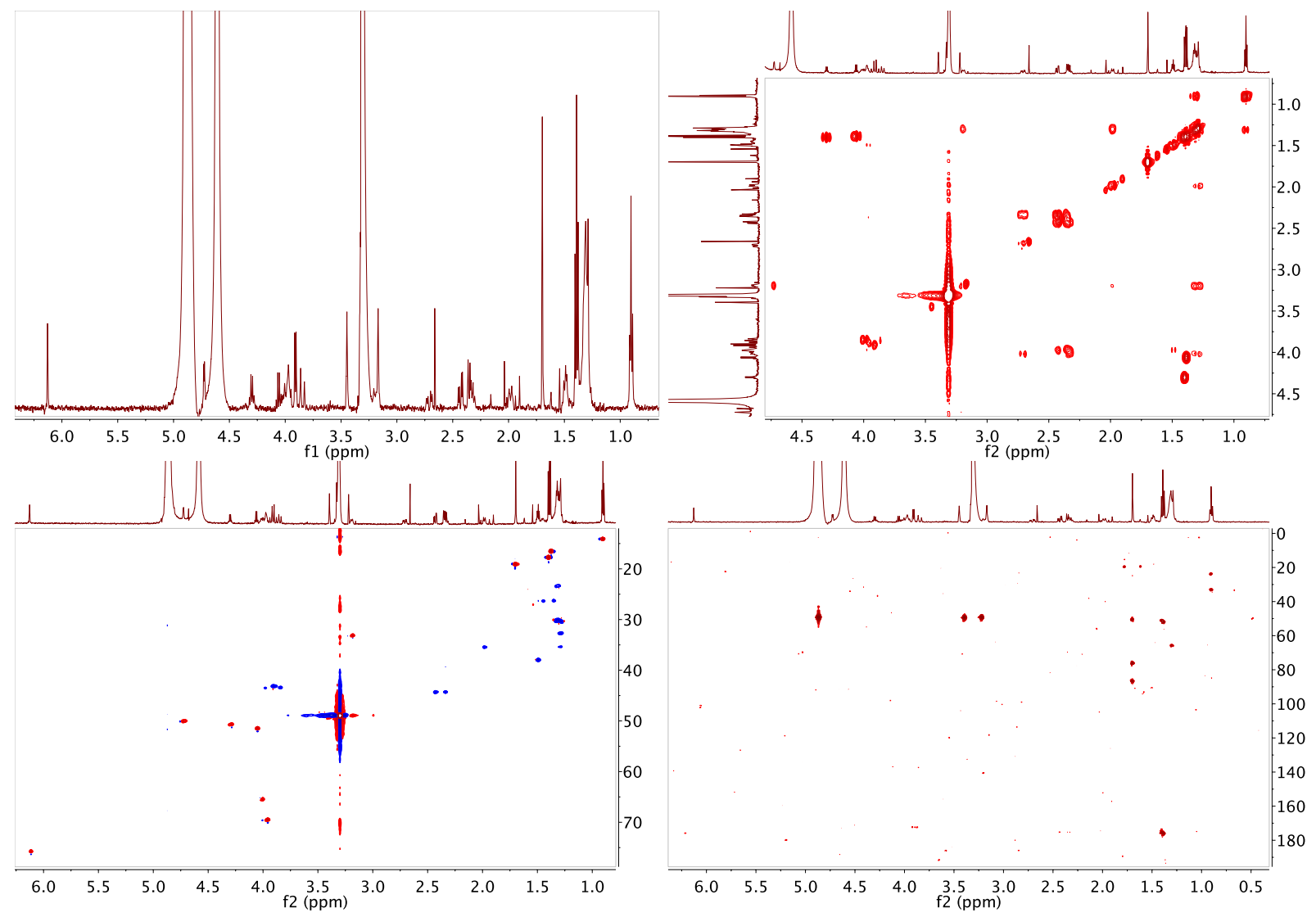

Figure S9. NMR of acybolin D in $\mathrm{MeOH}-d_{4}:{ }^{1} \mathrm{H}$ spectrum (top left), gCOSY (top right), gHSQC, DEPT-edited (bottom left), HMBC (bottom right). 


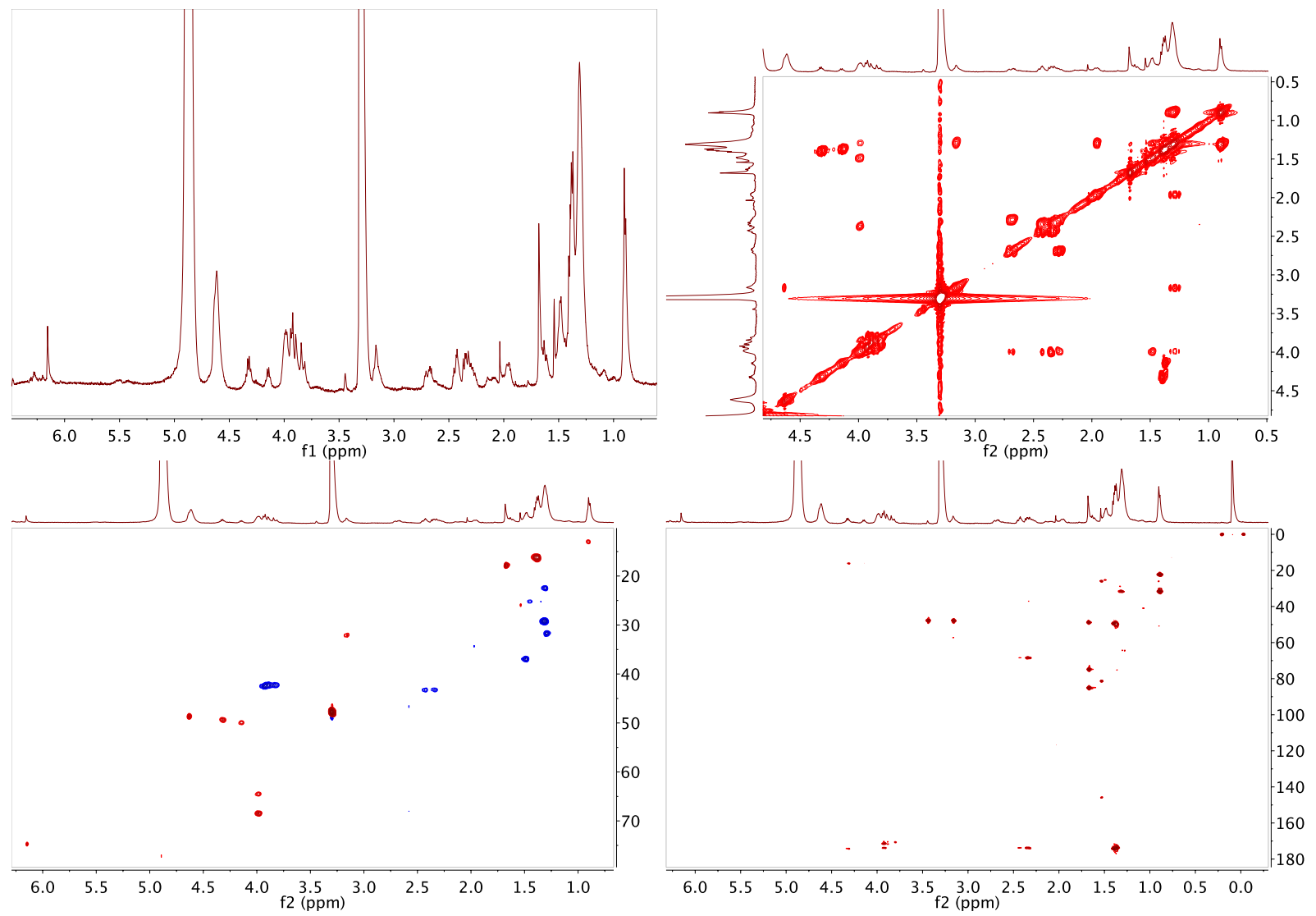

Figure S10. NMR of acybolin $\mathrm{E}$ in $\mathrm{MeOH}-d_{4}:{ }^{1} \mathrm{H}$ spectrum (top left), gCOSY (top right), gHSQC, DEPT-edited (bottom left), HMBC (bottom right). 


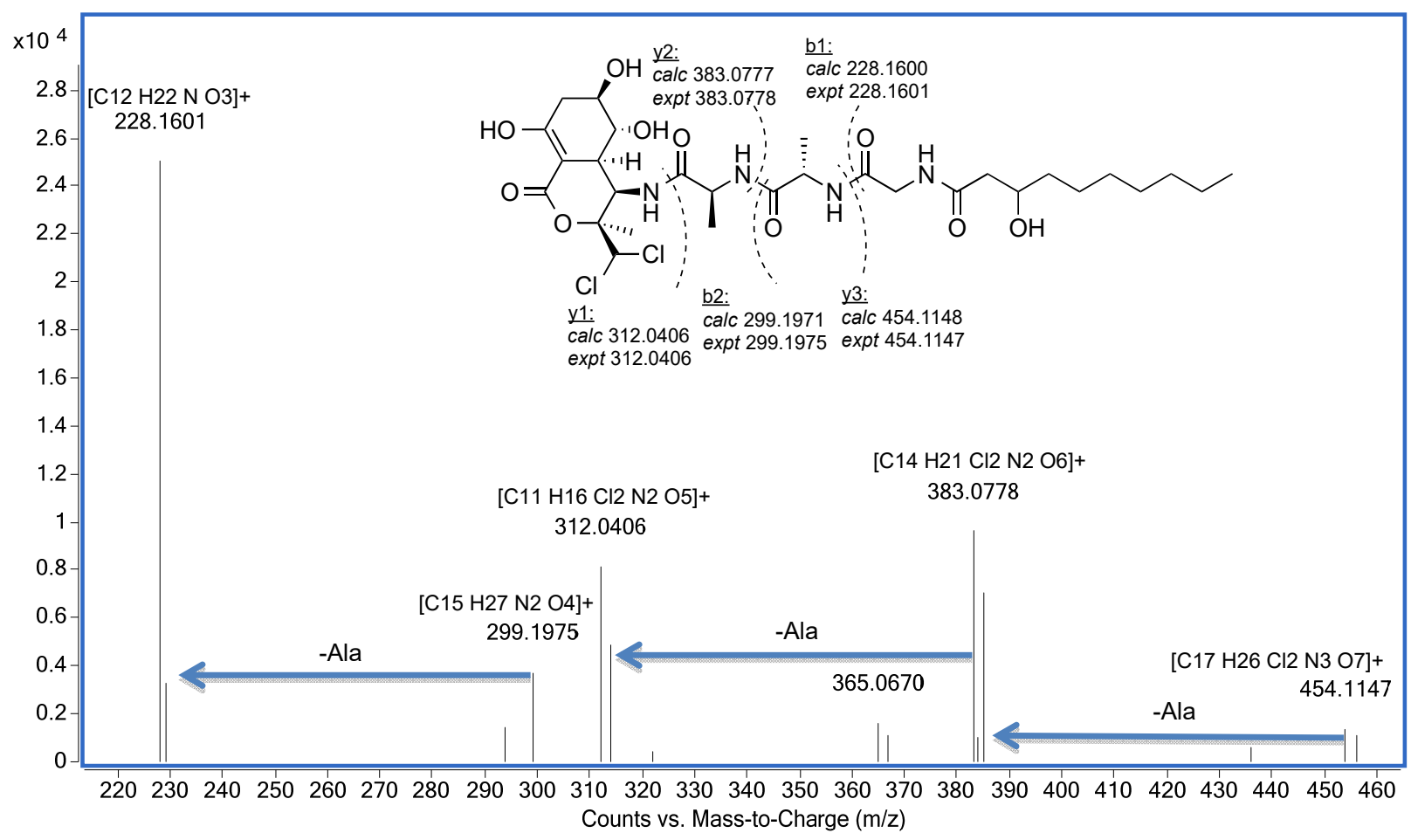

Figure S11. Tandem HR-MS analysis of acybolin F. Calculated and expected $\mathrm{m} / \mathrm{z}$ for the $\mathrm{N}$ acylated b1 and b2 ions, as well as the $C$-terminally-modified y1, y2, and y3 ions are shown. See Table S13. 


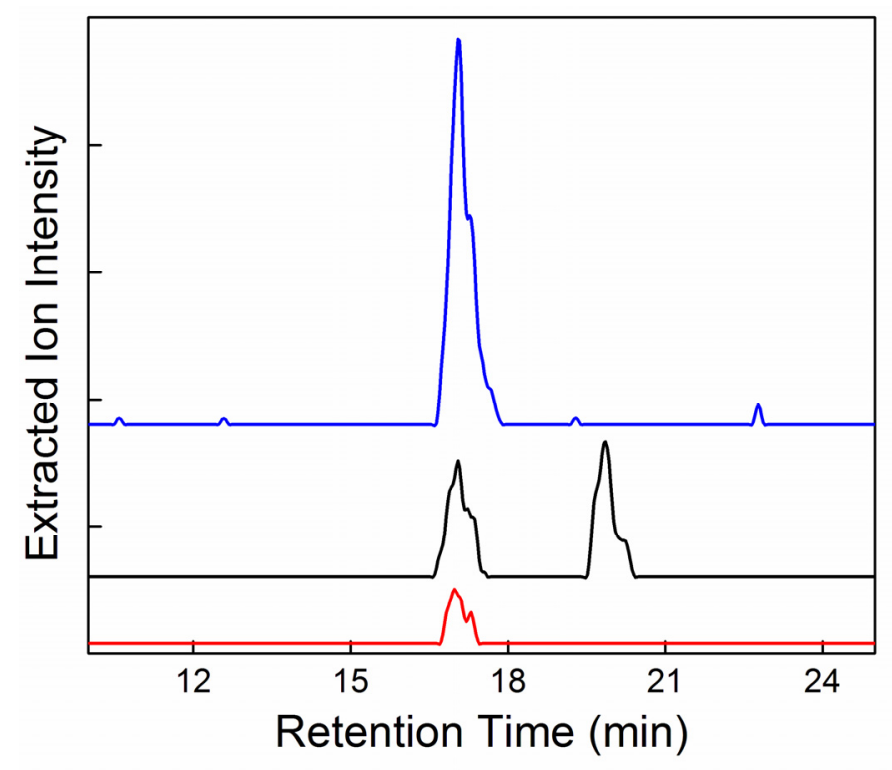

Figure S12. Marfey's analysis of acybolin A. Shown are the negative ion extraction intensities of derivatized L-Ala (blue trace), racemic DL-Ala (black trace), and Ala obtained from acybolin A (red trace). The data clearly show that the Ala residues in acybolin A bear the L-stereoconfiguration.<smiles>CCCCCCC[CH]C(C[OH2+])OC(=O)C(OC)(OC)c1ccccc1</smiles>

Figure S13. Structure of acybolin A MPTA ester annotated with $\Delta \delta^{\mathrm{SR}}$ values. The shifts indicate the $\mathrm{R}$ stereoconfiguration for the hydroxyl group on the acyl chain. 


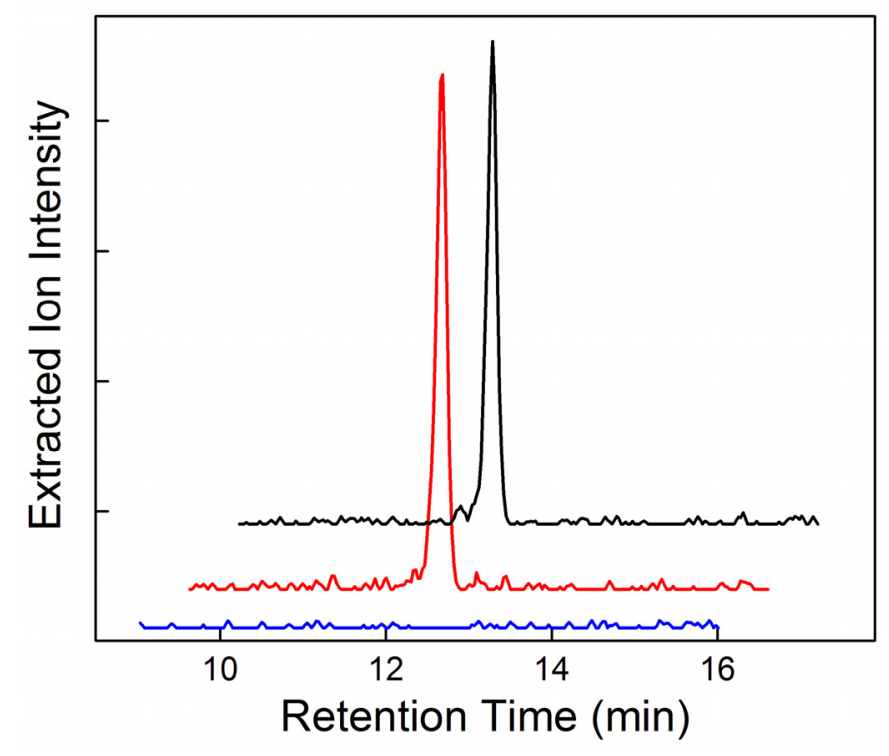

Figure S14. Assessment of acybolin production in $\triangle b t a Q$ B. thailandensis. Extracted ion intensities of acybolin C $(\mathbf{3 1}, \mathrm{m} / \mathrm{z}$ 793) with the $\triangle b t a Q$ mutant cultured in the absence of trimethoprim (blue trace), in the presence of trimethoprim (red trace), or of wt $B$. thailandensis grown in the presence of trimethoprim (black trace). The peak observed (red and black traces) corresponds to 31. Other acybolins were also observed in the $\triangle b t a Q$ mutant (data not shown). The traces have been offset in both axes for clarity. 
Table S1. HR-MS data for all compounds identified in the MS/MS network.

\begin{tabular}{|c|c|c|c|}
\hline Compound & {$[\mathrm{M}+\mathrm{H}]^{+}$calc } & {$[\mathrm{M}+\mathrm{H}]_{\text {obs }}^{+}$} & $\Delta \mathrm{ppm}$ \\
\hline Bactobolin A (1) & 383.0777 & 383.0769 & 2.1 \\
\hline Capistruin A (2) & 1025.0191 & 1025.0164 & 2.6 \\
\hline HMNQ (3) & 284.2014 & 284.2009 & 1.8 \\
\hline Burkholdac B (4) & 548.1923 & 548.1918 & 0.9 \\
\hline Terphenyl (5) & 293.1178 & 293.1166 & 4.1 \\
\hline Malleilactone A (6) & 307.1909 & 307.1900 & 2.9 \\
\hline Trimethoprim (7) & 291.1451 & 291.1448 & 1.0 \\
\hline Thailandamide A (8) & 718.4301 & 718.4310 & 1.2 \\
\hline HMHQ (9) & 256.1701 & 256.1694 & 2.7 \\
\hline HMOQ-N-oxide (10) & 286.1807 & 286.1797 & 3.5 \\
\hline HNQ (11) & 270.1858 & 270.1850 & 3.0 \\
\hline HMNQ-N-oxide (12) & 300.1964 & 300.1957 & 2.3 \\
\hline HMHQ-N-oxide (13) & 272.1651 & 272.1643 & 2.9 \\
\hline $\mathrm{HHQ}(14)$ & 242.1545 & 242.1538 & 2.9 \\
\hline HMUQ (15) & 312.2327 & 312.2320 & 2.2 \\
\hline HMNQ (16) & 286.2171 & 286.2164 & 2.4 \\
\hline HMNQ-N-oxide (17) & 302.2120 & 302.2114 & 2.0 \\
\hline HMHQ (18) & 258.1858 & 258.1856 & 0.8 \\
\hline Capistruin B (19) & 967.9976 & 967.9970 & 0.6 \\
\hline Capistruin C (20) & 894.4634 & 894.4636 & 0.2 \\
\hline Thailandamide C (21) & 718.4301 & 718.4310 & 1.2 \\
\hline Bactobolin I (22) & 511.1362 & 511.1350 & 2.3 \\
\hline Bactobolin B (23) & 454.1140 & 454.1148 & 1.8 \\
\hline Bactobolin C (24) & 367.0820 & 367.0825 & 1.4 \\
\hline Bactobolin D (25) & 438.1190 & 438.1192 & 0.5 \\
\hline Bactobolin E (26) & 525.1500 & 525.1501 & 0.2 \\
\hline Malleilactone B (27) & 323.1858 & 323.1848 & 3.1 \\
\hline Burkholdac A (28) & 534.1767 & 534.1770 & 0.6 \\
\hline Acybolin A (29) & 736.3091 & 736.3097 & 0.8 \\
\hline Acybolin B (30) & 752.3040 & 752.3030 & 1.3 \\
\hline
\end{tabular}




\begin{tabular}{cccc} 
Acybolin C (31) & 793.3306 & 793.3287 & 2.4 \\
Acybolin D (32) & 722.2935 & 722.2943 & 1.1 \\
Acybolin E (33) & 722.2935 & 722.2918 & 2.4 \\
Acybolin F (34) & 681.2669 & 681.2678 & 1.3 \\
Acybolin G (35) & 738.2884 & 738.2882 & 0.3 \\
Acybolin H (36) & 738.2884 & 738.2885 & 0.1 \\
Acybolin I (37) & 809.3255 & 809.3256 & 0.1 \\
Peptide (38) & 1056.5577 & 1056.5566 & 1.0 \\
Peptide (39) & 439.2920 & 439.2914 & 1.4 \\
Peptide (40) & 553.3350 & 553.3335 & 2.7 \\
\hline
\end{tabular}


Table S2. HR-MS/MS data for hydroxyalkylquinolines identified in this study. See Fig. S1 for fragmentation patterns.

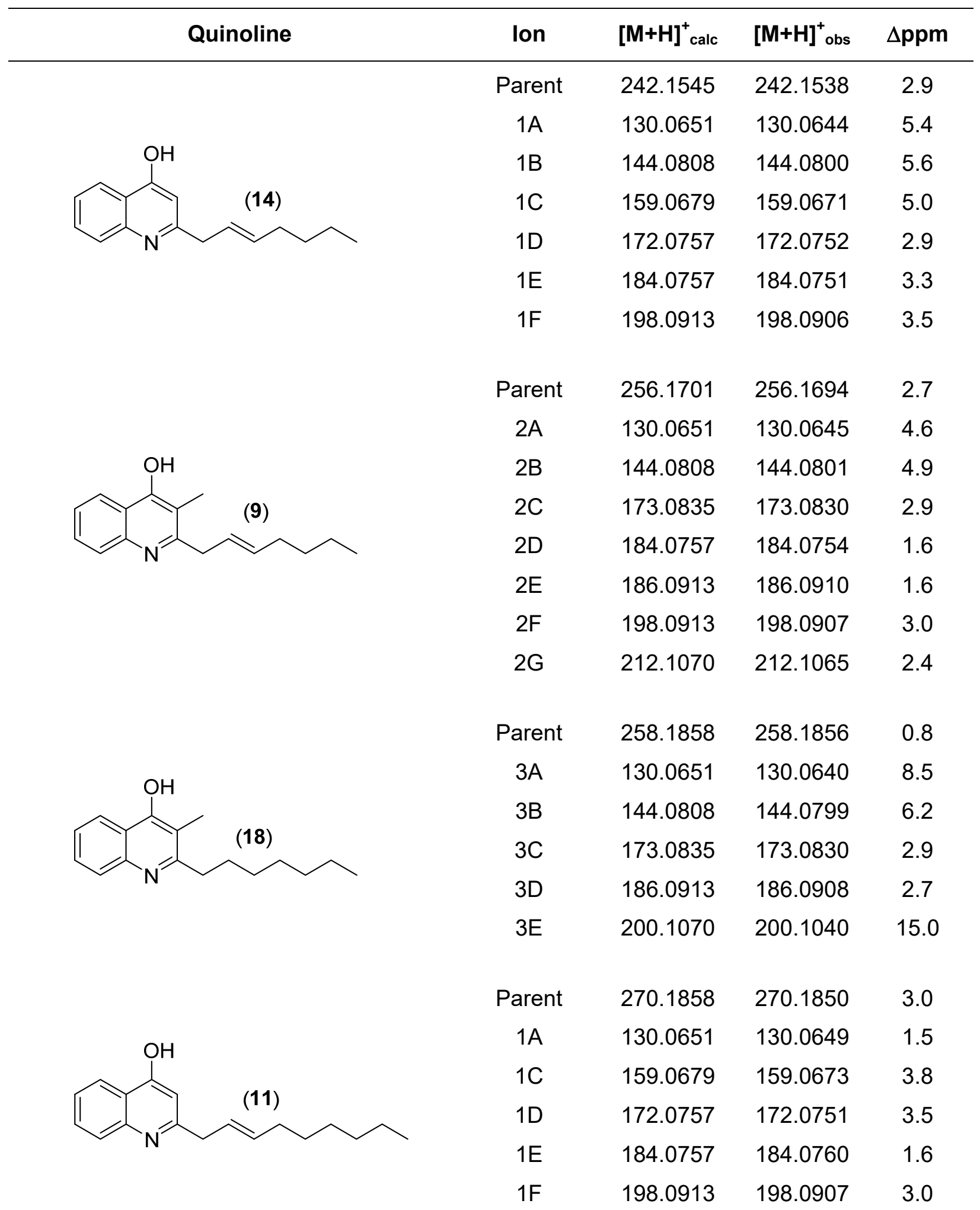



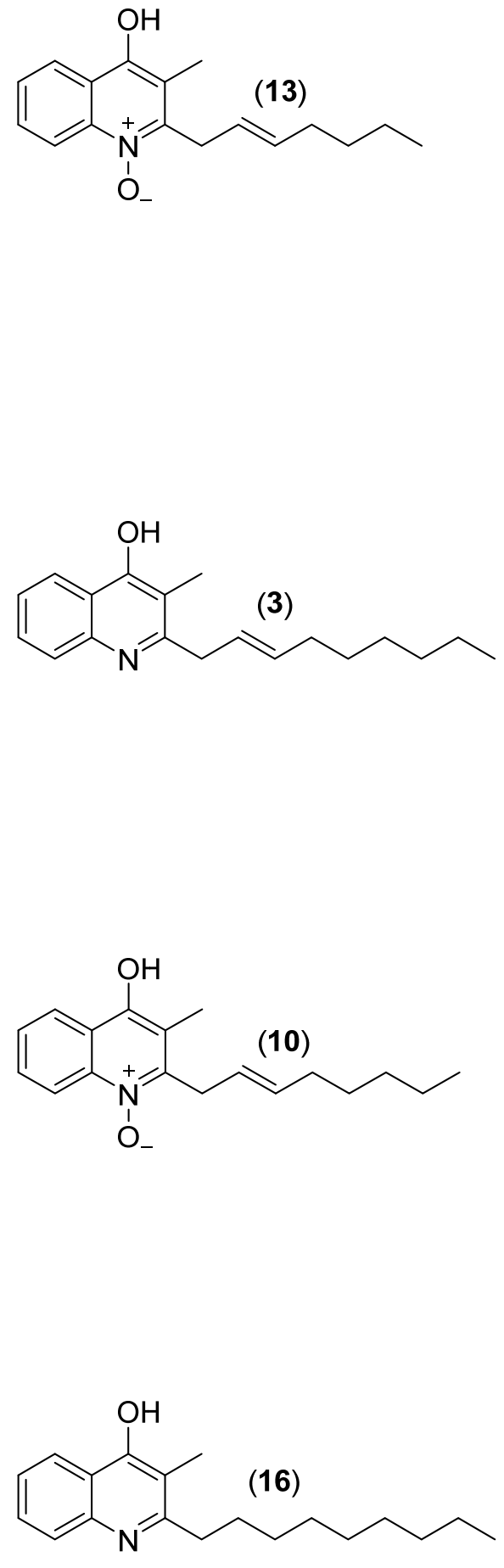

$\begin{array}{cccc}\text { Parent } & 272.1651 & 272.1643 & 2.9 \\ \text { 4A } & 130.0651 & 130.0646 & 3.8 \\ \text { 4B } & 144.0808 & 144.0798 & 6.9 \\ \text { 4C } & 172.0757 & 172.0745 & 7.0 \\ \text { 4D } & 184.0757 & 184.0751 & 3.3 \\ \text { 4E } & 186.0913 & 186.0920 & 3.8 \\ \text { 4F } & 198.0913 & 198.0904 & 4.5 \\ \text { 4G } & 212.1070 & 212.1069 & 0.5\end{array}$

Parent $\quad 284.2014 \quad 284.2007 \quad 2.5$

$\begin{array}{llll}2 A & 130.0651 & 130.0646 & 3.8\end{array}$

2B $\quad 144.0808 \quad 144.0801 \quad 4.9$

$\begin{array}{llll}2 \mathrm{C} & 173.0835 & 173.0830 & 2.9\end{array}$

2D $\quad 184.0757 \quad 184.0754 \quad 1.6$

2E $\quad 186.0913 \quad 186.0910 \quad 1.6$

$\begin{array}{llll}2 \mathrm{~F} & 198.0913 & 198.0907 & 3.0\end{array}$

$2 G \quad 212.1070 \quad 212.1063 \quad 3.3$

Parent $\quad 286.1807 \quad 286.1797 \quad 3.5$

$\begin{array}{llll}4 \mathrm{~A} & 130.0651 & 130.0645 & 4.6\end{array}$

$\begin{array}{llll}4 B & 144.0808 & 144.0802 & 4.2\end{array}$

$\begin{array}{llll}4 \mathrm{C} & 172.0757 & 172.0749 & 4.6\end{array}$

4D $\quad 184.0757 \quad 184.0750 \quad 3.8$

$\begin{array}{llll}4 \mathrm{~F} & 198.0913 & 198.0906 & 3.5\end{array}$

4G $\quad 212.1070 \quad 212.1060 \quad 4.7$

$\begin{array}{cccc}\text { Parent } & 286.2171 & 286.2164 & 2.4 \\ \text { 3A } & 130.0651 & 130.0646 & 3.8 \\ \text { 3B } & 144.0808 & 144.0802 & 4.2 \\ \text { 3C } & 173.0835 & 173.0831 & 2.3 \\ \text { 3D } & 186.0913 & 186.0908 & 2.7 \\ \text { 3E } & 200.107 & 200.1064 & 3.0\end{array}$




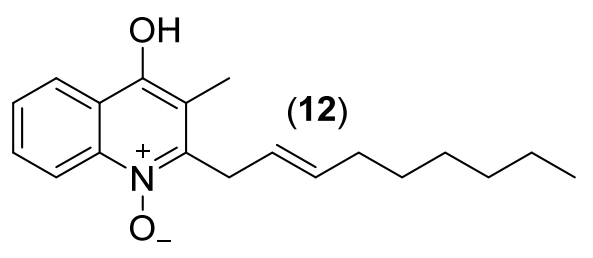

$\begin{array}{clll}\text { Parent } & 300.1964 & 300.1957 & 2.3 \\ \text { 4A } & 130.0651 & 130.0644 & 5.4 \\ \text { 4B } & 144.0808 & 144.0800 & 5.6 \\ \text { 4C } & 172.0757 & 172.0749 & 4.6 \\ \text { 4D } & 184.0757 & 184.0752 & 2.7 \\ \text { 4F } & 198.0913 & 198.0906 & 3.5 \\ \text { 4G } & 212.1070 & 212.1065 & 2.4\end{array}$

$\begin{array}{llll}\text { Parent } & 302.2120 & 302.2114 & 2.0\end{array}$

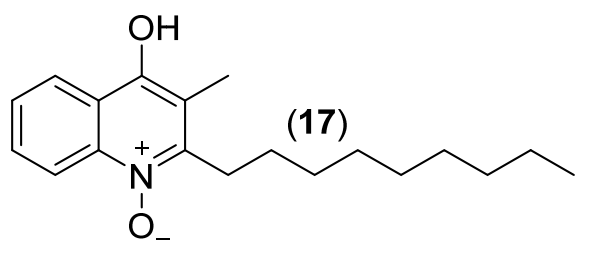

$\begin{array}{llll}5 A & 130.0651 & 130.0643 & 6.2\end{array}$

$\begin{array}{llll}5 B & 144.0808 & 144.0799 & 6.2\end{array}$

$\begin{array}{llll}5 \mathrm{C} & 173.0835 & 173.0831 & 2.3\end{array}$

$\begin{array}{llll}5 D & 186.0913 & 186.0907 & 3.2\end{array}$

$\begin{array}{llll}5 E & 200.1070 & 200.1064 & 3.0\end{array}$

Parent $\quad 312.2327 \quad 312.2320 \quad 2.2$

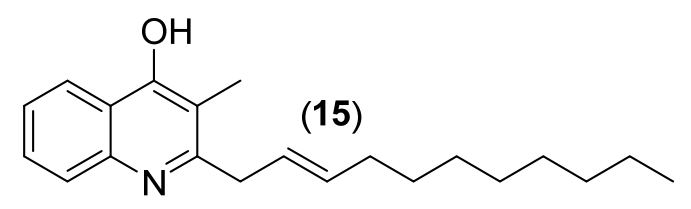

$\begin{array}{llll}2 \mathrm{~A} & 130.0651 & 130.0646 & 3.8\end{array}$

$\begin{array}{llll}2 B & 144.0808 & 144.0802 & 4.2\end{array}$

$\begin{array}{llll}2 \mathrm{C} & 173.0835 & 173.0831 & 2.3\end{array}$

2D $\quad 184.0757 \quad 184.0755 \quad 1.1$

2E $\quad \begin{array}{llll}186.0913 & 186.0910 & 1.6\end{array}$

$\begin{array}{llll}2 F & 198.0913 & 198.0910 & 1.5\end{array}$

2G $\quad 212.1070 \quad 212.1066 \quad 1.9$ 
Table S3. NMR data for capistruin B.

\begin{tabular}{|c|c|c|}
\hline Residue & Atom & $\delta$ \\
\hline \multirow{3}{*}{$G^{1}$} & $\mathrm{H}$ & 8.19 \\
\hline & $\mathrm{C}_{\alpha}$ & 42.2 \\
\hline & $\mathrm{H}_{\alpha}$ & $3.28,3.64$ \\
\hline \multirow{7}{*}{$T^{2}$} & $\mathrm{H}$ & 7.68 \\
\hline & $\mathrm{C}_{\alpha}$ & 56.3 \\
\hline & $\mathrm{H}_{\alpha}$ & 4.49 \\
\hline & $\mathrm{C}_{\beta}$ & 67.1 \\
\hline & $\mathrm{H}_{\beta}$ & 3.81 \\
\hline & $\mathrm{C}_{\mathrm{V}}$ & 18.3 \\
\hline & $\mathrm{H}_{\mathrm{V}}$ & 0.93 \\
\hline \multirow{8}{*}{$P^{3}$} & $\mathrm{C}_{\alpha}$ & 61.5 \\
\hline & $\mathrm{H}_{\alpha}$ & 3.99 \\
\hline & $\mathrm{C}_{\beta}$ & 29.5 \\
\hline & $\mathrm{H}_{\beta}$ & $1.61,2.01$ \\
\hline & $\mathrm{C}_{\mathrm{Y}}$ & 24.80 \\
\hline & $\mathrm{H}_{\mathrm{Y}}$ & $1.64,1.89$ \\
\hline & $\mathrm{C}_{\delta}$ & 47.9 \\
\hline & $\mathrm{H}_{\delta}$ & $3.44,3.72$ \\
\hline \multirow{3}{*}{$G^{4}$} & $\mathrm{H}$ & 7.76 \\
\hline & $\mathrm{C}_{\alpha}$ & 42.5 \\
\hline & $\mathrm{H}_{\alpha}$ & $3.18,3.38$ \\
\hline \multirow{12}{*}{$\mathrm{F}^{5}$} & $\mathrm{H}$ & 8.47 \\
\hline & $\mathrm{C}_{\alpha}$ & 54.6 \\
\hline & $\mathrm{H}_{\alpha}$ & 4.56 \\
\hline & $\mathrm{C}_{\beta}$ & 37.7 \\
\hline & $\mathrm{H}_{\beta}$ & $2.47,3.15$ \\
\hline & $C_{Y}$ & 136.5 \\
\hline & $\mathrm{C}_{\delta}$ & 129.4 \\
\hline & $\mathrm{H}_{\delta}$ & 6.95 \\
\hline & $\mathrm{C}_{\varepsilon}$ & 128.4 \\
\hline & $\mathrm{H}_{\varepsilon}$ & 7.05 \\
\hline & $\mathrm{C}_{\zeta}$ & 126.8 \\
\hline & $\mathrm{H}_{\zeta}$ & 7.00 \\
\hline \multirow{7}{*}{$Q^{6}$} & $\mathrm{H}$ & 7.77 \\
\hline & $\mathrm{C}_{\alpha}$ & 55.2 \\
\hline & $\mathrm{H}_{\alpha}$ & 4.23 \\
\hline & $\mathrm{C}_{\beta}$ & 27.4 \\
\hline & $\mathrm{H}_{\beta}$ & $1.61,1.84$ \\
\hline & $\mathrm{C}_{\mathrm{Y}}$ & 31.6 \\
\hline & $\mathrm{H}_{\mathrm{Y}}$ & $1.93,2.05$ \\
\hline
\end{tabular}




\begin{tabular}{|c|c|c|}
\hline \multirow{7}{*}{$\mathrm{T}^{7}$} & $\overline{\mathrm{H}}$ & 7.55 \\
\hline & $\mathrm{C}_{\alpha}$ & 56.3 \\
\hline & $\mathrm{H}_{\alpha}$ & 4.48 \\
\hline & $\mathrm{C}_{\beta}$ & 67.8 \\
\hline & $\mathrm{H}_{\beta}$ & 3.73 \\
\hline & $\mathrm{C}_{\mathrm{y}}$ & 14.5 \\
\hline & $H_{\gamma}$ & 0.74 \\
\hline \multirow{8}{*}{$P^{8}$} & $\mathrm{C}_{\alpha}$ & 61.3 \\
\hline & $\mathrm{H}_{\alpha}$ & 4.48 \\
\hline & $\mathrm{C}_{\beta}$ & 29.5 \\
\hline & $\mathrm{H}_{\beta}$ & $1.68,1.99$ \\
\hline & $\mathrm{C}_{y}$ & 25.0 \\
\hline & $\mathrm{H}_{\gamma}$ & $1.60,1.85$ \\
\hline & $\mathrm{C}_{\delta}$ & 48.8 \\
\hline & $\mathrm{H}_{\delta}$ & $3.54,3.64$ \\
\hline \multirow{5}{*}{$D^{9}$} & $\mathrm{H}$ & 8.39 \\
\hline & $\mathrm{C}_{\alpha}$ & 48.3 \\
\hline & $\mathrm{H}_{\alpha}$ & 4.65 \\
\hline & $\mathrm{C}_{\beta}$ & 35.2 \\
\hline & $\mathrm{H}_{\beta}$ & $2.75,3.25$ \\
\hline \multirow{4}{*}{$A^{10}$} & $\mathrm{C}_{\alpha}$ & 15.95 \\
\hline & $\mathrm{H}_{\alpha}$ & 3.85 \\
\hline & $\mathrm{C}_{\beta}$ & 16.0 \\
\hline & $\mathrm{H}_{\beta}$ & 1.15 \\
\hline \multirow{10}{*}{$\mathrm{R}^{11}$} & $\mathrm{H}$ & 7.78 \\
\hline & $\mathrm{C}_{\alpha}$ & 54.3 \\
\hline & $\mathrm{H}_{\alpha}$ & 4.37 \\
\hline & $\mathrm{C}_{\beta}$ & 32.4 \\
\hline & $\mathrm{H}_{\beta}$ & $1.51,1.70$ \\
\hline & $\mathrm{C}_{\mathrm{y}}$ & 24.7 \\
\hline & $\mathrm{H}_{\mathrm{\gamma}}$ & $1.33,1.37$ \\
\hline & $\mathrm{C}_{\delta}$ & 37.4 \\
\hline & $\mathrm{H}_{\delta}$ & 2.98 \\
\hline & $\mathrm{H}_{\varepsilon}$ & 7.12 \\
\hline \multirow{9}{*}{$V^{12}$} & $\mathrm{H}$ & 8.03 \\
\hline & $\mathrm{C}_{\alpha}$ & 56.3 \\
\hline & $\mathrm{H}_{\alpha}$ & 4.48 \\
\hline & $\mathrm{C}_{\beta}$ & 34.3 \\
\hline & $\mathrm{H}_{\beta}$ & 1.93 \\
\hline & $\mathrm{C}_{\mathrm{y} 1}$ & 15.3 \\
\hline & $\mathrm{H}_{\mathrm{Y} 1}$ & 0.24 \\
\hline & $\mathrm{C}_{\mathrm{Y} 2}$ & 19.2 \\
\hline & $\mathrm{H}_{\mathrm{y} 2}$ & 0.57 \\
\hline$I^{13}$ & $\mathrm{H}$ & 8.06 \\
\hline
\end{tabular}




\begin{tabular}{|c|c|c|}
\hline & $\mathrm{C}_{\alpha}$ & 61.1 \\
\hline & $\mathrm{H}_{\alpha}$ & 3.21 \\
\hline & $\mathrm{C}_{\beta}$ & 32.7 \\
\hline & $\mathrm{H}_{\beta}$ & 1.51 \\
\hline & $C_{y 1}$ & 24.7 \\
\hline & $H_{y_{1}}$ & $0.94,1.21$ \\
\hline & $\mathrm{C}_{\mathrm{y} 2}$ & 14.8 \\
\hline & $\mathrm{H}_{\mathrm{Y} 2}$ & 0.46 \\
\hline & $\mathrm{C}_{\delta 1}$ & 8.6 \\
\hline & $\mathrm{H}_{\delta 1}$ & 0.49 \\
\hline \multirow{5}{*}{$S^{14}$} & $\mathrm{H}$ & 7.78 \\
\hline & $\mathrm{C}_{\alpha}$ & 54.4 \\
\hline & $\mathrm{H}_{\alpha}$ & 5.00 \\
\hline & $\mathrm{C}_{\beta}$ & 64.9 \\
\hline & $\mathrm{H}_{\beta}$ & 3.54 \\
\hline \multirow{10}{*}{$\mathrm{R}^{15}$} & $\mathrm{H}$ & 7.87 \\
\hline & $\mathrm{C}_{\alpha}$ & 53.2 \\
\hline & $\mathrm{H}_{\alpha}$ & 4.34 \\
\hline & $\mathrm{C}_{\beta}$ & 29.1 \\
\hline & $\mathrm{H}_{\beta}$ & 1.40 \\
\hline & $\mathrm{C}_{\mathrm{V}}$ & 23.7 \\
\hline & $\mathrm{H}_{\gamma}$ & $1.05,1.14$ \\
\hline & $\mathrm{C}_{\delta}$ & 40.7 \\
\hline & $\mathrm{H}_{\delta}$ & $2.74,2.80$ \\
\hline & $\mathrm{H}_{\varepsilon}$ & 6.82 \\
\hline \multirow{12}{*}{$\mathrm{F}^{16}$} & $\mathrm{H}$ & 8.20 \\
\hline & $\mathrm{C}_{\alpha}$ & 54.9 \\
\hline & $\mathrm{H}_{\alpha}$ & 4.41 \\
\hline & $\mathrm{C}_{\beta}$ & 37.7 \\
\hline & $H_{\beta}$ & $2.56,2.90$ \\
\hline & $\mathrm{C}_{\gamma}$ & 135.8 \\
\hline & $\mathrm{C}_{\delta}$ & 129.0 \\
\hline & $\mathrm{H}_{\delta}$ & 7.01 \\
\hline & $\mathrm{C}_{\varepsilon}$ & 128.6 \\
\hline & $\mathrm{H}_{\varepsilon}$ & 7.11 \\
\hline & $\mathrm{C}_{\zeta}$ & 7.05 \\
\hline & $\mathrm{H}_{\zeta}$ & 127.1 \\
\hline \multirow{3}{*}{$\mathrm{G}^{17}$} & $\mathrm{H}$ & 8.19 \\
\hline & $\mathrm{C}_{\alpha}$ & 42.2 \\
\hline & $\mathrm{H}_{\alpha}$ & $3.29,3.66$ \\
\hline \multirow{4}{*}{$F^{18}$} & $\mathrm{H}$ & 7.37 \\
\hline & $\mathrm{C}_{\alpha}$ & 56.1 \\
\hline & $\mathrm{H}_{\alpha}$ & 4.24 \\
\hline & $\mathrm{C}_{\beta}$ & 37.4 \\
\hline
\end{tabular}




\begin{tabular}{|c|c|c|}
\hline \multirow{4}{*}{} & $\mathrm{H}_{\beta}$ & $2.72,2.98$ \\
\cline { 2 - 3 } & $\mathrm{C}_{\mathrm{Y}}$ & 137.2 \\
\cline { 2 - 3 } & $\mathrm{C}_{\delta}$ & 129.0 \\
\cline { 2 - 3 } & $\mathrm{H}_{\delta}$ & 6.99 \\
\cline { 2 - 3 } & $\mathrm{C}_{\varepsilon}$ & 128.4 \\
\cline { 2 - 3 } & $\mathrm{H}_{\varepsilon}$ & 7.06 \\
\cline { 2 - 3 } & $\mathrm{C}_{\zeta}$ & 128.5 \\
\cline { 2 - 3 } & $\mathrm{H}_{\zeta}$ & 7.05 \\
\hline
\end{tabular}


Table S4. NMR data for capistruin C.

\begin{tabular}{|c|c|c|}
\hline Residue & Atom & $\delta$ \\
\hline \multirow{3}{*}{$\mathrm{G}^{1}$} & $\mathrm{H}$ & 8.01 \\
\hline & $\mathrm{C}_{\alpha}$ & 43.0 \\
\hline & $\mathrm{H}_{\alpha}$ & $3.41,3.52$ \\
\hline \multirow{7}{*}{$\mathrm{T}^{2}$} & $\mathrm{H}$ & 7.58 \\
\hline & $\mathrm{C}_{\alpha}$ & 56.0 \\
\hline & $\mathrm{H}_{\alpha}$ & 4.49 \\
\hline & $\mathrm{C}_{\beta}$ & 67.0 \\
\hline & $\mathrm{H}_{\beta}$ & 3.80 \\
\hline & $\mathrm{C}_{Y}$ & 18.4 \\
\hline & $\mathrm{H}_{\mathrm{v}}$ & 0.95 \\
\hline \multirow{8}{*}{$P^{3}$} & $\mathrm{C}_{\alpha}$ & 61.5 \\
\hline & $\mathrm{H}_{\alpha}$ & 3.99 \\
\hline & $\mathrm{C}_{\beta}$ & 29.4 \\
\hline & $\mathrm{H}_{\beta}$ & $1.60,2.02$ \\
\hline & $\mathrm{C}_{\mathrm{y}}$ & 24.6 \\
\hline & $\mathrm{H}_{\mathrm{y}}$ & $1.65,1.90$ \\
\hline & $\mathrm{C}_{\delta}$ & 47.7 \\
\hline & $\mathrm{H}_{\delta}$ & $3.45,3.65$ \\
\hline \multirow{3}{*}{$\mathrm{G}^{4}$} & $\mathrm{H}$ & 7.76 \\
\hline & $\mathrm{C}_{\alpha}$ & 42.5 \\
\hline & $\mathrm{H}_{\alpha}$ & $3.23,3.39$ \\
\hline \multirow{12}{*}{$\mathrm{F}^{5}$} & $\mathrm{H}$ & 8.48 \\
\hline & $\mathrm{C}_{\alpha}$ & 54.5 \\
\hline & $\mathrm{H}_{\alpha}$ & 4.57 \\
\hline & $\mathrm{C}_{\beta}$ & 37.7 \\
\hline & $\mathrm{H}_{\beta}$ & $2.47,3.15$ \\
\hline & $\mathrm{C}_{\mathrm{y}}$ & 136.5 \\
\hline & $\mathrm{C}_{\delta}$ & 129.4 \\
\hline & $\mathrm{H}_{\delta}$ & 6.95 \\
\hline & $\mathrm{C}_{\varepsilon}$ & 128.4 \\
\hline & $\mathrm{H}_{\varepsilon}$ & 7.06 \\
\hline & $\mathrm{C}_{\zeta}$ & 126.9 \\
\hline & $\mathrm{H}_{\zeta}$ & 7.01 \\
\hline \multirow{5}{*}{$Q^{6}$} & $\mathrm{H}$ & 7.78 \\
\hline & $\mathrm{C}_{\alpha}$ & 55.1 \\
\hline & $\mathrm{H}_{\alpha}$ & 4.22 \\
\hline & $\mathrm{C}_{\beta}$ & 31.7 \\
\hline & $\mathrm{H}_{\beta}$ & $1.88,2.08$ \\
\hline \multirow{3}{*}{$T^{7}$} & $\mathrm{H}$ & 7.63 \\
\hline & $\mathrm{C}_{\beta}$ & 67.8 \\
\hline & $\mathrm{H}_{\beta}$ & 3.72 \\
\hline
\end{tabular}




\begin{tabular}{|c|c|c|}
\hline & $\mathrm{C}_{\mathrm{y}}$ & 17.2 \\
\hline & $\mathrm{H}_{\mathrm{v}}$ & 0.73 \\
\hline \multirow{8}{*}{$\mathrm{P}^{8}$} & $\overline{C_{\alpha}}$ & 61.3 \\
\hline & $\mathrm{H}_{\alpha}$ & 4.47 \\
\hline & $\mathrm{C}_{\beta}$ & 29.5 \\
\hline & $\mathrm{H}_{\beta}$ & $1.68,2.00$ \\
\hline & $\mathrm{C}_{\mathrm{y}}$ & 27.6 \\
\hline & $\mathrm{H}_{V}$ & $1.61,1.85$ \\
\hline & $\mathrm{C}_{\delta}$ & 48.6 \\
\hline & $\mathrm{H}_{\delta}$ & $3.53,3.63$ \\
\hline \multirow{5}{*}{$D^{9}$} & $\mathrm{H}$ & 8.36 \\
\hline & $\mathrm{C}_{a}$ & 48.4 \\
\hline & $\mathrm{H}_{\mathrm{a}}$ & 4.78 \\
\hline & $\mathrm{C}_{\beta}$ & 35.4 \\
\hline & $\mathrm{H}_{\beta}$ & $2.90,3.35$ \\
\hline \multirow{5}{*}{$A^{10}$} & $\mathrm{H}$ & 7.98 \\
\hline & $\mathrm{C}_{\alpha}$ & 52.0 \\
\hline & $\mathrm{H}_{\alpha}$ & 3.85 \\
\hline & $\mathrm{C}_{\beta}$ & 15.9 \\
\hline & $\mathrm{H}_{\beta}$ & 1.15 \\
\hline \multirow{10}{*}{$\mathrm{R}^{11}$} & $\mathrm{H}$ & 7.83 \\
\hline & $\mathrm{C}_{\alpha}$ & 54.2 \\
\hline & $\mathrm{H}_{\alpha}$ & 4.37 \\
\hline & $\mathrm{C}_{\beta}$ & 32.0 \\
\hline & $\mathrm{H}_{\beta}$ & $1.50,1.69$ \\
\hline & $C_{\gamma}$ & 24.6 \\
\hline & $\mathrm{H}_{\mathrm{Y}}$ & $1.33,1.38$ \\
\hline & $\mathrm{C}_{\delta}$ & 40.1 \\
\hline & $\mathrm{H}_{\delta}$ & 2.98 \\
\hline & $\mathrm{H}_{\varepsilon}$ & 7.12 \\
\hline \multirow{9}{*}{$V^{12}$} & $\mathrm{H}$ & 8.03 \\
\hline & $\mathrm{C}_{\alpha}$ & 56.2 \\
\hline & $\mathrm{H}_{\alpha}$ & 4.49 \\
\hline & $\mathrm{C}_{\beta}$ & 34.3 \\
\hline & $\mathrm{H}_{\beta}$ & 1.94 \\
\hline & $C_{Y 1}$ & 15.3 \\
\hline & $\mathrm{H}_{\mathrm{y} 1}$ & 0.27 \\
\hline & $\mathrm{C}_{\mathrm{y} 2}$ & 19.2 \\
\hline & $\mathrm{H}_{\mathrm{Y} 2}$ & 0.57 \\
\hline \multirow{5}{*}{$I^{13}$} & $\mathrm{H}$ & 8.14 \\
\hline & $\mathrm{C}_{\alpha}$ & 61.07 \\
\hline & $\mathrm{H}_{\alpha}$ & 3.22 \\
\hline & $\mathrm{C}_{\beta}$ & 32.9 \\
\hline & $\mathrm{H}_{\beta}$ & 1.52 \\
\hline
\end{tabular}




\begin{tabular}{|c|c|c|}
\hline & $\mathrm{C}_{\mathrm{y} 1}$ & 14.6 \\
\hline & $\mathrm{H}_{\mathrm{y} 1}$ & 0.48 \\
\hline & $\mathrm{C}_{\mathrm{\gamma} 2}$ & 24.8 \\
\hline & $\mathrm{H}_{\mathrm{y} 2}$ & $0.94,1.20$ \\
\hline & $\mathrm{C}_{\delta}$ & 8.8 \\
\hline & $\mathrm{H}_{\delta}$ & 0.50 \\
\hline \multirow{5}{*}{$S^{14}$} & $\mathrm{H}$ & 7.79 \\
\hline & $\mathrm{C}_{\alpha}$ & 54.4 \\
\hline & $\mathrm{H}_{\alpha}$ & 4.98 \\
\hline & $\mathrm{C}_{\beta}$ & 64.5 \\
\hline & $\mathrm{H}_{\beta}$ & $3.48,3.59$ \\
\hline \multirow{10}{*}{$\mathrm{R}^{15}$} & $\mathrm{H}$ & 7.92 \\
\hline & $\mathrm{C}_{\alpha}$ & 61.3 \\
\hline & $\mathrm{H}_{\alpha}$ & 4.46 \\
\hline & $\mathrm{C}_{\beta}$ & 32.1 \\
\hline & $\mathrm{H}_{\beta}$ & 1.49 \\
\hline & $\mathrm{C}_{\mathrm{Y}}$ & 23.4 \\
\hline & $\mathrm{H}_{V}$ & 1.16 \\
\hline & $\mathrm{C}_{\delta}$ & 40.5 \\
\hline & $\mathrm{H}_{\delta}$ & 2.88 \\
\hline & $\mathrm{H} \varepsilon$ & 6.88 \\
\hline \multirow{12}{*}{$\mathrm{F}^{16}$} & $\mathrm{H}$ & 7.97 \\
\hline & $\mathrm{C}_{\alpha}$ & 54.9 \\
\hline & $\mathrm{H}_{\alpha}$ & 4.40 \\
\hline & $\mathrm{C}_{\beta}$ & 37.6 \\
\hline & $\mathrm{H}_{\beta}$ & $2.66,2.96$ \\
\hline & $\mathrm{C}_{\mathrm{Y}}$ & 136.1 \\
\hline & $\mathrm{C}_{\delta}$ & 129.0 \\
\hline & $\mathrm{H}_{\delta}$ & 7.02 \\
\hline & $\mathrm{C} \varepsilon$ & 128.6 \\
\hline & $\mathrm{H} \varepsilon$ & 7.11 \\
\hline & $\mathrm{C}_{\zeta}$ & 126.9 \\
\hline & $\mathrm{H}_{3}^{2}$ & 7.05 \\
\hline \multirow{3}{*}{$\mathrm{G}^{17}$} & $\mathrm{H}$ & 8.02 \\
\hline & $\mathrm{C}_{\alpha}$ & 43.1 \\
\hline & $H_{\alpha}$ & $3.38,3.51$ \\
\hline
\end{tabular}


Table S5. Summary of CYANA structure calculation parameters for capistruins B and C.

\begin{tabular}{c|c|c}
\hline \hline Parameter & Capistruin B & Capistruin C \\
\hline \hline $\begin{array}{c}\text { \# of distance constraints used for final structure } \\
\text { calculation }\end{array}$ & 84 & 193 \\
\hline Average target function (f) & $\begin{array}{c}4.18 \mathrm{E}-2 \\
+/-2.12 \mathrm{E}-2\end{array}$ & $\begin{array}{c}6.15 \mathrm{E}-2 \\
+/-1.58 \mathrm{E}-3\end{array}$ \\
\hline Average backbone RMSD to mean & $2.79 \AA+/-0.43$ & $0.18 \AA+/-0.04$ \\
\hline \# of violated distance constraints & 1 & 2 \\
\hline \# of violated van der Waals constraints & 0 & 0 \\
\hline \hline
\end{tabular}




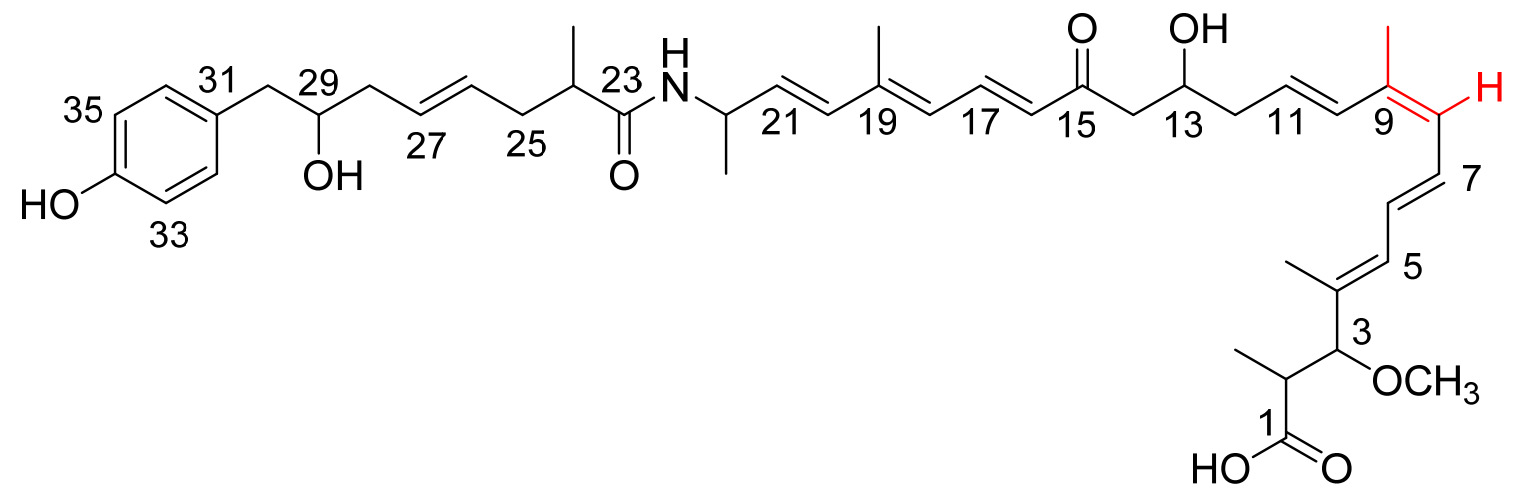

Table S6. NMR spectral data for thailandamide C. The structure of thailandamide $C$ is shown above.

\begin{tabular}{|c|c|c|c|c|}
\hline $\mathrm{C} / \mathrm{H}$ & $\delta_{H}$ & Multiplicity (Hz) & $\delta_{c}$ & HMBC \\
\hline 1 & & & 180.2 & \\
\hline 2 & 3.13 & $\mathrm{~m}$ & 40.4 & C3 \\
\hline 2-Me & 1.17 & $d(6.1)$ & 8.8 & $\mathrm{C} 2$ \\
\hline 3 & 3.68 & $\mathrm{~m}$ & 91.3 & $\mathrm{C} 7$ \\
\hline 3-OMe & 3.13 & s & 56.0 & C3 \\
\hline 4 & & & 135.4 & \\
\hline 4-Me & 1.69 & $\mathrm{~s}$ & 10.7 & $\mathrm{C} 3, \mathrm{C} 4, \mathrm{C} 7$ \\
\hline 5 & 6.18 & $d$ & 132.3 & \\
\hline 6 & 6.52 & $\mathrm{dd}(14.5,11.2)$ & 128.9 & \\
\hline 7 & 6.63 & $\mathrm{~m}$ & 130.8 & \\
\hline 8 & 6.12 & $d(11.4)$ & 131.2 & 9-Me \\
\hline 9 & & & 136.6 & \\
\hline 9-Me & 1.89 & s & 12.6 & $\mathrm{C} 8, \mathrm{C} 9, \mathrm{C} 10$ \\
\hline 10 & 6.21 & $d$ & 138.5 & $\mathrm{C9}$ \\
\hline 11 & 5.80 & $\mathrm{dt}(15.2,7.4)$ & 126.2 & $\mathrm{C9}$ \\
\hline 12 & 2.36 & $\mathrm{~m}$ & 41.4 & C10, C11, C13, C14 \\
\hline 13 & 4.16 & $\mathrm{~m}$ & 69.2 & \\
\hline 14 & 2.76 & $\mathrm{~m}$ & 48.0 & C12, C13, C15 \\
\hline 15 & & & 201.6 & \\
\hline 16 & 6.26 & $d$ & 134.0 & C18, C19 \\
\hline 17 & 7.66 & dd $(15.1,11.7)$ & 140.2 & C15 \\
\hline
\end{tabular}




\begin{tabular}{|c|c|c|c|c|}
\hline 18 & 6.21 & $d$ & 129.9 & C16 \\
\hline 19 & & & 146.2 & \\
\hline 19-Me & 1.96 & $\mathrm{~s}$ & 13.1 & C16, C18, C19 \\
\hline 20 & 6.27 & $d(7.1)$ & 130.4 & $\mathrm{C} 18, \mathrm{C} 19, \mathrm{C} 22,19-\mathrm{Me}$ \\
\hline 21 & 5.94 & $\mathrm{~m}$ & 135.8 & $\mathrm{C} 19, \mathrm{C} 22$ \\
\hline 22 & 4.55 & $\mathrm{~m}$ & 47.4 & $\mathrm{C} 21,22-\mathrm{Me}$ \\
\hline 22-Me & 1.24 & $d$ & 1.24 & $\mathrm{C} 21, \mathrm{C} 22$ \\
\hline 23 & & & 178.0 & \\
\hline 24 & 2.40 & $\mathrm{~m}$ & 42.1 & \\
\hline 24-Me & 1.11 & $d(6.9)$ & 17.7 & C23, C24, C25 \\
\hline 25 & $2.09,2.29$ & $\mathrm{~m}$ & 38.2 & $\mathrm{C} 24, \mathrm{C} 26$ \\
\hline 26 & 5.43 & $\mathrm{dt}(14.8,7.1)$ & 130.9 & \\
\hline 27 & 5.51 & $\mathrm{dt}(14.3,6.9)$ & 129.8 & C25, C26 \\
\hline 28 & 2.10 & $\mathrm{~m}$ & 240.8 & C26, C27, C29 \\
\hline 29 & 3.68 & $\mathrm{~m}$ & 73.4 & $\mathrm{C} 27$ \\
\hline 30 & 2.59 & $d(5.7)$ & 43.0 & C29, C31 \\
\hline 31 & & & 131.4 & \\
\hline $32 / 36$ & 6.98 & $d(8.4)$ & 131.2 & C30, C31, C33, C35 \\
\hline $33 / 35$ & 6.69 & $d(8.5)$ & 115.7 & C31, C32, C34, C36 \\
\hline 34 & & & 130.7 & \\
\hline
\end{tabular}




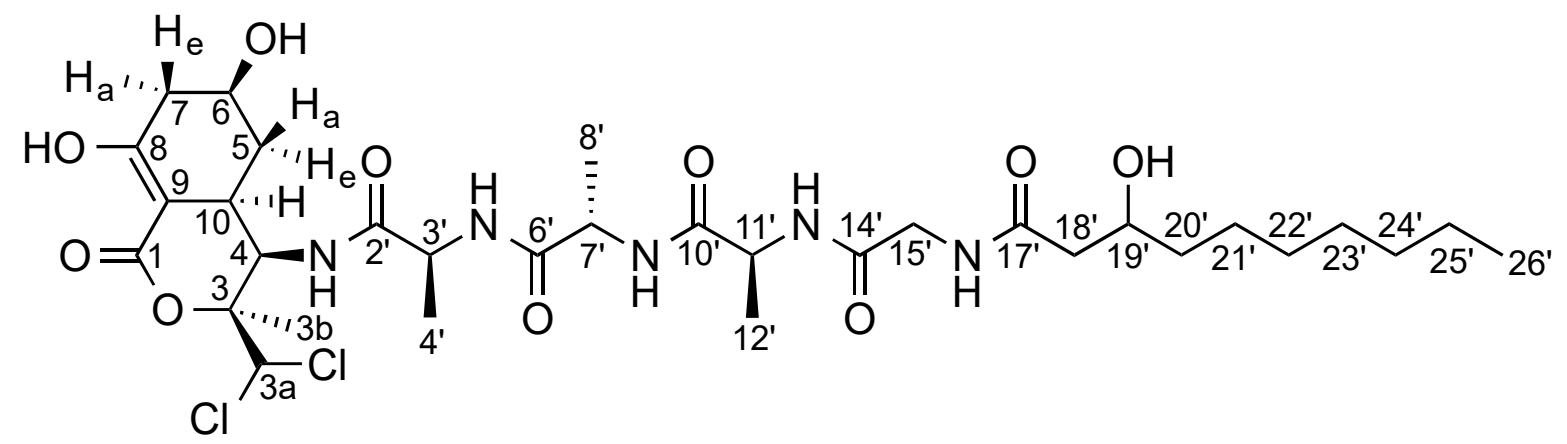

Table S7. NMR spectral data for acybolin A. The structure of acybolin A is shown above.

\begin{tabular}{|c|c|c|c|c|}
\hline $\mathrm{C} / \mathrm{H}$ & $\delta_{H}$ & Multiplicity (Hz) & $\delta_{c}$ & HMBC \\
\hline 1 & & & 170.5 & \\
\hline 3 & & & 86.5 & \\
\hline $3 a$ & 6.29 & $s$ & 76.3 & $\mathrm{C} 3, \mathrm{C} 3 \mathrm{~b}, \mathrm{C} 4$ \\
\hline $3 b$ & 1.68 & $\mathrm{~s}$ & 19.3 & C3, C3a, C4 \\
\hline 4 & 4.65 & $d(3.7)$ & 50.2 & $\mathrm{C} 3 \mathrm{~b}, \mathrm{C} 10, \mathrm{C} 9, \mathrm{C} 2$ \\
\hline $5\left(\mathrm{H}_{\mathrm{a}}\right)$ & 1.97 & $\mathrm{~m}$ & 35.8 & C6 \\
\hline $5\left(\mathrm{H}_{\mathrm{e}}\right)$ & 1.30 & & 35.8 & $\mathrm{C} 6, \mathrm{C} 10, \mathrm{C} 7, \mathrm{C} 4$ \\
\hline 6 & 3.99 & & 65.9 & \\
\hline $7\left(\mathrm{H}_{\mathrm{e}}\right)$ & 2.69 & $\mathrm{dd}(6.1,18.2)$ & 39.7 & C6, C9, C8, C5 \\
\hline $7\left(\mathrm{H}_{\mathrm{a}}\right)$ & 2.32 & dd & 39.7 & C6, C8 \\
\hline 8 & & & 177.6 & \\
\hline 9 & & & 92.9 & \\
\hline 10 & 3.17 & $\mathrm{~m}$ & 33.5 & \\
\hline $2^{\prime}$ & & & 175.5 & \\
\hline $3^{\prime}$ & 4.36 & $q(7.3)$ & 50.6 & C2', C4' \\
\hline $4^{\prime}$ & 1.42 & $d(7.3)$ & 18.1 & C3', C2' \\
\hline $6^{\prime}$ & & & 176.1 & \\
\hline $7^{\prime}$ & 4.19 & $q(7.3)$ & 51.76 & C6', C8', \\
\hline $8^{\prime}$ & 1.37 & $\mathrm{~d}(7.3)$ & 17.3 & C6', C7' \\
\hline $10^{\prime}$ & & & 175.24 & \\
\hline $11^{\prime}$ & 4.08 & $q(7.4)$ & 51.75 & C10', C12' \\
\hline $12^{\prime}$ & 1.39 & $\mathrm{~d}(7.4)$ & 17.1 & C10', C11' \\
\hline
\end{tabular}




\begin{tabular}{|c|c|c|c|c|}
\hline $14^{\prime}$ & & & 172.9 & \\
\hline $15^{\prime}\left(\mathrm{H}_{\mathrm{a}}\right)$ & 3.94 & $d(16.6)$ & 44.0 & C14', C17' \\
\hline $15^{\prime}\left(H_{b}\right)$ & 3.80 & $d(16.6)$ & 44.0 & C14', C17' \\
\hline $17^{\prime}$ & & & 175.18 & \\
\hline $18^{\prime}\left(\mathrm{H}_{\mathrm{a}}\right)$ & 2.45 & $\mathrm{dd}(4.8,14.6)$ & 44.5 & C20', C19', C17' \\
\hline $18^{\prime}\left(H_{b}\right)$ & 2.33 & dd & 44.5 & C20', C19', C17' \\
\hline $19^{\prime}$ & 3.97 & & 69.9 & \\
\hline $20^{\prime}$ & 1.50 & & 38.3 & C21', C22', C19' \\
\hline $21^{\prime}\left(\mathrm{H}_{\mathrm{a}}\right)$ & 1.44 & & 26.7 & $\mathrm{C} 22^{\prime}$ \\
\hline $21^{\prime}\left(H_{b}\right)$ & 1.35 & & 26.7 & C22' \\
\hline $22^{\prime}$ & 1.32 & & 30.7 & C21', C23' \\
\hline $23^{\prime}$ & & & 30.42 & \\
\hline $24^{\prime}$ & 1.30 & & 33.0 & $\mathrm{C} 25^{\prime}$ \\
\hline $25^{\prime}$ & 1.31 & & 23.7 & C26' \\
\hline $26^{\prime}$ & 0.90 & & 14.5 & C25', C24' \\
\hline
\end{tabular}




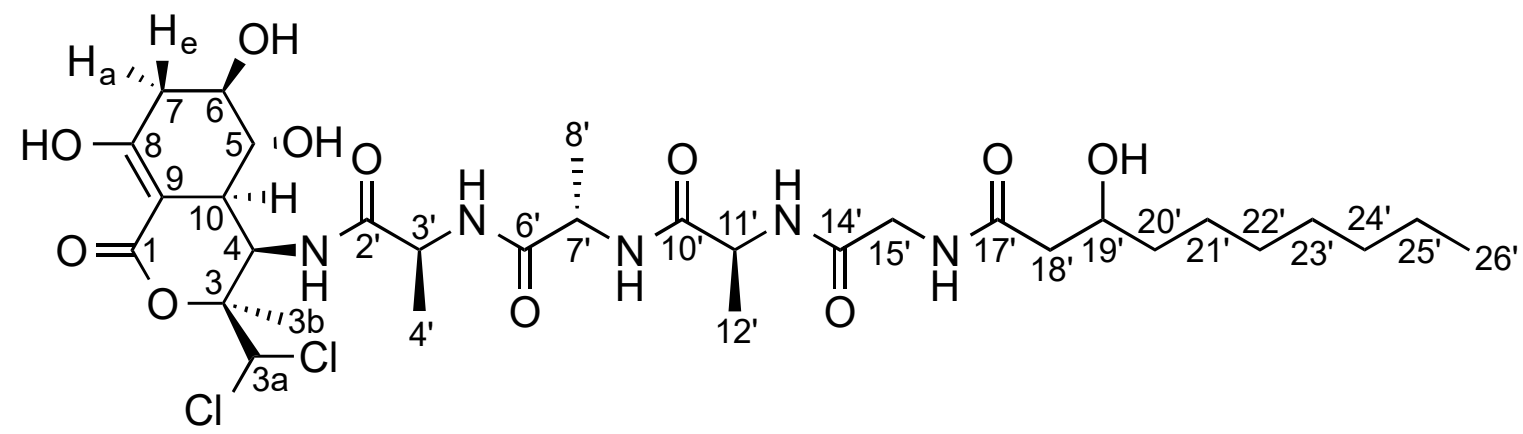

Table S8. NMR spectral data for acybolin B. The structure of acybolin B is shown above.

\begin{tabular}{|c|c|c|c|c|}
\hline $\mathrm{C} / \mathrm{H}$ & $\delta_{H}$ & Multiplicity (Hz) & $\delta_{c}$ & HMBC \\
\hline \multicolumn{5}{|l|}{1} \\
\hline 3 & & & 85.2 & \\
\hline $3 a$ & 6.29 & $\mathrm{~s}$ & 74.7 & $\mathrm{C} 3 \mathrm{~b}, \mathrm{C} 4, \mathrm{C} 3$ \\
\hline $3 b$ & 1.64 & s & 17.8 & $\mathrm{C} 4, \mathrm{C} 3 \mathrm{a}, \mathrm{C} 3$ \\
\hline 4 & 4.81 & $d(3.5)$ & 46.7 & C10 \\
\hline 5 & 3.18 & $\mathrm{t}(9.3)$ & 71 & \\
\hline 6 & 3.79 & & 68.6 & $\mathrm{C} 5$ \\
\hline $7\left(\mathrm{H}_{\mathrm{e}}\right)$ & 2.75 & $\mathrm{dd}(6.5,18.5)$ & 37 & $\mathrm{C} 8$ \\
\hline $7\left(\mathrm{H}_{\mathrm{a}}\right)$ & 2.4 & & 37 & \\
\hline 8 & & & 175.4 & \\
\hline 9 & & & 89.1 & \\
\hline 10 & 2.89 & $\mathrm{~m}$ & 38.8 & \\
\hline $2^{\prime}$ & & & 174.7 & \\
\hline $3^{\prime}$ & 4.34 & $\mathrm{q}(7.2)$ & 49.2 & $\mathrm{C} 4^{\prime}, \mathrm{C} 2^{\prime}$ \\
\hline $4^{\prime}$ & 1.41 & $d(7.1)$ & 16.6 & C3' \\
\hline $6^{\prime}$ & & & 174.6 & \\
\hline $7^{\prime}$ & 4.16 & $q(7.3)$ & 50.3 & C6', C8' \\
\hline $8^{\prime}$ & 1.35 & $d(7.4)$ & 15.8 & \\
\hline $10^{\prime}$ & & & 173.8 & \\
\hline $11^{\prime}$ & 4.04 & $q(7.3)$ & 50.3 & C10', C12' \\
\hline $12^{\prime}$ & 1.37 & $d(7.5)$ & 15.5 & C11' \\
\hline $14^{\prime}$ & & & 171.5 & \\
\hline 15' $\left(H_{a}\right)$ & 3.93 & $d(16.4)$ & 42.5 & C14', C17' \\
\hline
\end{tabular}




\begin{tabular}{|c|c|c|c|c|}
\hline $15^{\prime}\left(H_{b}\right)$ & 3.77 & $d(16.5)$ & 42.5 & C14', C17' \\
\hline $17^{\prime}$ & & & 173.7 & \\
\hline $18^{\prime}\left(\mathrm{H}_{\mathrm{a}}\right)$ & 2.41 & $\mathrm{dd}(4.7,14.1)$ & 43.1 & C17', C19', C20' \\
\hline $18^{\prime}\left(H_{b}\right)$ & 2.31 & $\mathrm{dd}(8.1,14.1)$ & 43.1 & C17', C19', C20' \\
\hline \multirow[t]{2}{*}{$19^{\prime}$} & 3.95 & & 68.4 & $\mathrm{C} 21^{\prime}$ \\
\hline & & & & C19', C18', C22', \\
\hline $20^{\prime}$ & 1.47 & $\mathrm{~m}$ & 36.9 & $\mathrm{C} 21^{\prime}$ \\
\hline $21^{\prime}\left(\mathrm{H}_{\mathrm{a}}\right)$ & 1.42 & & 25.2 & C22' \\
\hline $21^{\prime}\left(H_{b}\right)$ & 1.31 & & 25.2 & C22' \\
\hline $22^{\prime}$ & 1.29 & & 29.1 & $\mathrm{C} 24^{\prime}$ \\
\hline \multicolumn{5}{|l|}{$23^{\prime}$} \\
\hline $24^{\prime}$ & 1.27 & & 31.5 & \\
\hline $25^{\prime}$ & 1.287 & & 22.3 & \\
\hline $26^{\prime}$ & 0.88 & $\mathrm{t}(7.0)$ & 12.9 & C25', C24' \\
\hline
\end{tabular}




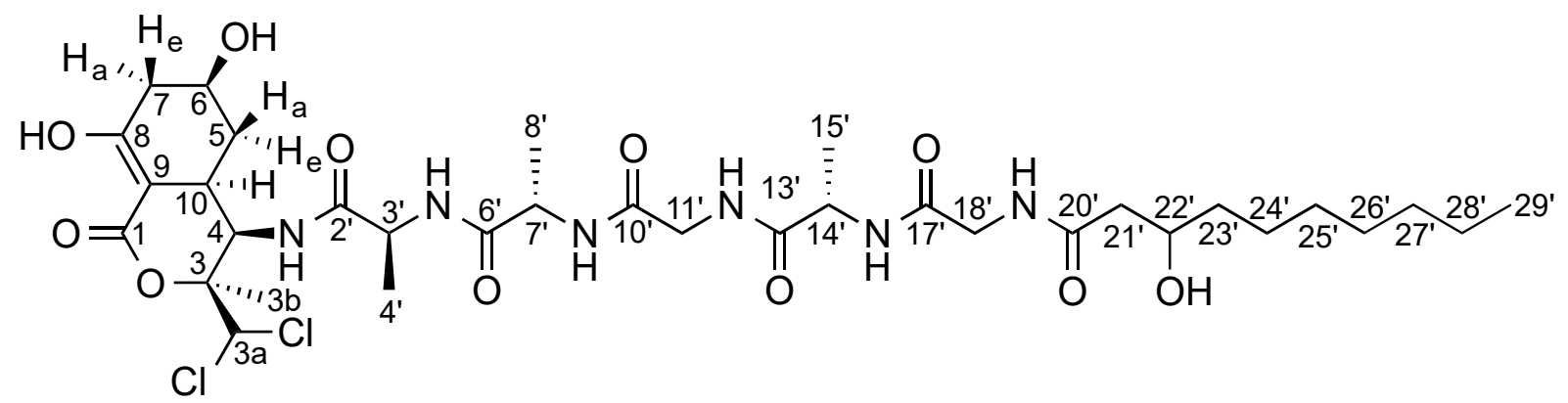

Table S9. NMR spectral data for acybolin C. The structure of acybolin C is shown above.

\begin{tabular}{|c|c|c|c|c|}
\hline $\mathrm{C} / \mathrm{H}$ & $\delta_{H}$ & Multiplicity (Hz) & $\delta_{c}$ & HMBC \\
\hline \multicolumn{5}{|l|}{1} \\
\hline 3 & & & 86.2 & \\
\hline $3 a$ & 6.26 & $\mathrm{~s}$ & 75.9 & C3b, C3 \\
\hline $3 b$ & 1.66 & $\mathrm{~s}$ & 19 & $\mathrm{C} 3, \mathrm{C} 3 \mathrm{a}, \mathrm{C} 4$ \\
\hline 4 & 4.63 & $d(3.8)$ & 49.9 & $\mathrm{C} 10, \mathrm{C} 9, \mathrm{C} 2 \mathrm{\prime}$ \\
\hline $5\left(\mathrm{H}_{\mathrm{a}}\right)$ & 1.95 & $\mathrm{~m}$ & 35.5 & \\
\hline $5\left(\mathrm{H}_{\mathrm{e}}\right)$ & 1.27 & & 35.5 & C6 \\
\hline 6 & 3.98 & $\mathrm{~m}$ & 65.6 & \\
\hline $7\left(\mathrm{H}_{\mathrm{e}}\right)$ & 2.68 & $\mathrm{dd}(6.0,17.5)$ & 39.1 & C5, C6, C8 \\
\hline $7\left(\mathrm{H}_{\mathrm{a}}\right)$ & 2.28 & dd & 39.1 & C6 \\
\hline 8 & & & 177.5 & \\
\hline 9 & & & 92.5 & \\
\hline 10 & 3.16 & $\mathrm{~m}$ & 33.2 & \\
\hline $2^{\prime}$ & & & 175.2 & \\
\hline $3^{\prime}$ & 4.34 & $q(7.4)$ & 50.4 & C4', C2' \\
\hline $4^{\prime}$ & 1.39 & $d(7.0)$ & 17.5 & C2' \\
\hline $6^{\prime}$ & & & 174.8 & \\
\hline $7^{\prime}$ & 4.15 & $q(7.0)$ & 51.1 & C8', C6' \\
\hline $8^{\prime}$ & 1.36 & $d(7.1)$ & 17.1 & C7', C6' \\
\hline $10^{\prime}$ & & & 171.7 & \\
\hline $11^{\prime}\left(H_{a}\right)$ & 3.78 & & 43.67 & C13', C10' \\
\hline $11^{\prime}\left(H_{b}\right)$ & & & & \\
\hline
\end{tabular}




\begin{tabular}{|c|c|c|c|c|}
\hline $13^{\prime}$ & & & 176.1 & \\
\hline $14^{\prime}$ & 4.25 & $q(7.4)$ & 51.3 & C15', C13' \\
\hline $15^{\prime}$ & 1.39 & $d(7.0)$ & 17.1 & C14', C13' \\
\hline $17^{\prime}$ & & & 171.9 & \\
\hline $18^{\prime}\left(\mathrm{H}_{\mathrm{a}}\right)$ & 3.94 & $d(16.8)$ & 43.5 & C17', C20' \\
\hline $18^{\prime}\left(H_{b}\right)$ & 3.82 & $d(18.4)$ & 43.5 & C17', C20' \\
\hline $20^{\prime}$ & & & 174.8 & \\
\hline $21^{\prime}\left(\mathrm{H}_{\mathrm{a}}\right)$ & 2.41 & $\mathrm{dd}(4.2,14.0)$ & 44.3 & C22', C20' \\
\hline $21^{\prime}\left(\mathrm{H}_{\mathrm{b}}\right)$ & 2.3 & $\mathrm{dd}(8.7,14.0)$ & 44.3 & C23', C22', C20' \\
\hline $22^{\prime}$ & 3.95 & $\mathrm{~m}$ & 69.6 & \\
\hline $23^{\prime}$ & 1.48 & & 38.1 & C22', C24' \\
\hline $24^{\prime}\left(\mathrm{H}_{\mathrm{a}}\right)$ & 1.43 & & 26.4 & $\mathrm{C} 25^{\prime}$ \\
\hline $24^{\prime}\left(\mathrm{H}_{\mathrm{b}}\right)$ & 1.34 & & 26.4 & $\mathrm{C} 25^{\prime}$ \\
\hline $25^{\prime}$ & 1.303 & & 30.2 & C24' \\
\hline $26^{\prime}$ & 1.31 & & & $\mathrm{C} 25^{\prime}$ \\
\hline $27^{\prime}$ & 1.28 & & 32.7 & C28' \\
\hline $28^{\prime}$ & 1.3 & & 23.4 & C29', C27' \\
\hline $29^{\prime}$ & 0.89 & $t(6.9)$ & 14.3 & C28', C27' \\
\hline
\end{tabular}




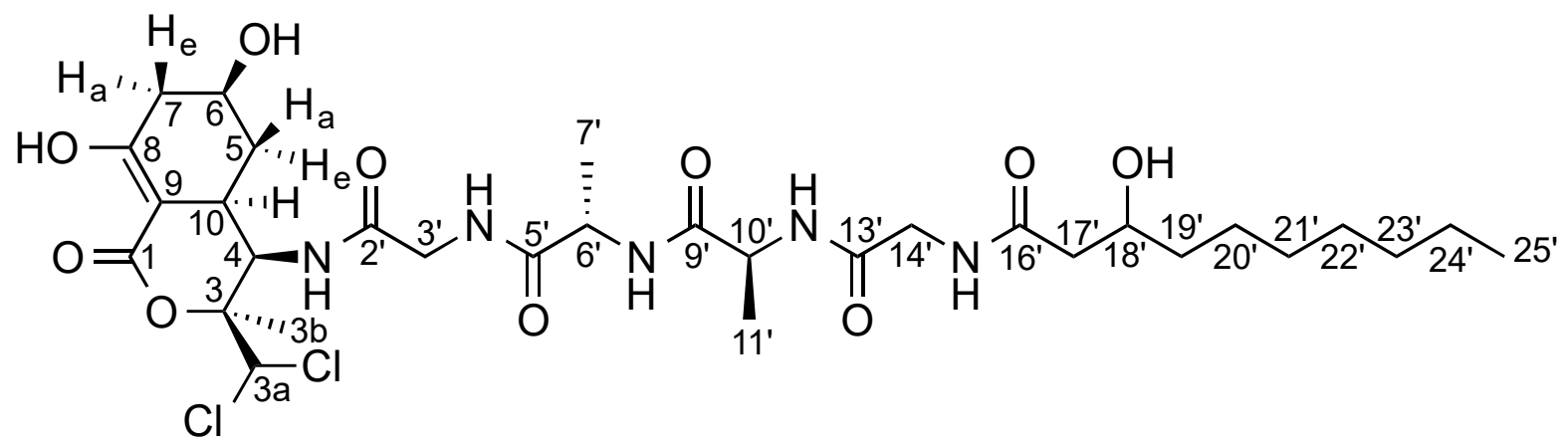

Table S10. NMR spectral data for acybolin D. The structure of acybolin D is shown above.

\begin{tabular}{|c|c|c|c|c|}
\hline $\mathrm{C} / \mathrm{H}$ & $\delta_{H}$ & Multiplicity (Hz) & $\delta_{c}$ & HMBC \\
\hline \multicolumn{5}{|l|}{1} \\
\hline 3 & & & 86.3 & \\
\hline $3 a$ & 6.13 & $\mathrm{~s}$ & 75.8 & \\
\hline $3 b$ & 1.7 & $\mathrm{~s}$ & 19.2 & $\mathrm{C} 4, \mathrm{C} 3 \mathrm{a}, \mathrm{C} 3$ \\
\hline 4 & 4.73 & $d(3.7)$ & 50.1 & \\
\hline $5\left(\mathrm{H}_{\mathrm{a}}\right)$ & 1.98 & $\mathrm{~m}$ & 35.5 & \\
\hline $5\left(\mathrm{H}_{\mathrm{e}}\right)$ & 1.3 & & 35.5 & $\mathrm{C} 6$ \\
\hline 6 & 4.02 & $\mathrm{~m}$ & 65.5 & \\
\hline $7\left(\mathrm{H}_{\mathrm{e}}\right)$ & 2.71 & $\mathrm{dd}(6.5,18.2)$ & 39.3 & \\
\hline $7\left(\mathrm{H}_{\mathrm{a}}\right)$ & 2.34 & & 39.3 & \\
\hline \multicolumn{5}{|l|}{8} \\
\hline \multicolumn{5}{|l|}{9} \\
\hline 10 & 3.19 & $\mathrm{~m}$ & 33.2 & \\
\hline $2^{\prime}$ & & & 172.4 & \\
\hline $3^{\prime}$ & 3.91 & $d(5.8)$ & 43.2 & C2', C5' \\
\hline $5^{\prime}$ & & & 176.2 & \\
\hline $6^{\prime}$ & 4.06 & $q(7.3)$ & 51.5 & C5' \\
\hline $7^{\prime}$ & 1.38 & $\mathrm{~d}(7.2)$ & 16.6 & C5', C6' \\
\hline $9^{\prime}$ & & & 175.8 & \\
\hline $10^{\prime}$ & 4.3 & $q(6.4)$ & 50.7 & C9' \\
\hline $11^{\prime}$ & 1.4 & $d(6.9)$ & 17.8 & C9', C10' \\
\hline \multicolumn{5}{|l|}{$13^{\prime}$} \\
\hline $14^{\prime}\left(\mathrm{H}_{\mathrm{a}}\right)$ & 3.99 & $\mathrm{~m}$ & 43.5 & \\
\hline
\end{tabular}




\begin{tabular}{ccccc}
$14^{\prime}\left(\mathrm{H}_{\mathrm{b}}\right)$ & 3.85 & $\mathrm{~d}(16.8)$ & 43.5 & $\mathrm{C}^{\prime} 6^{\prime}$ \\
$16^{\prime}$ & & & 175.3 & \\
$17^{\prime}\left(\mathrm{H}_{\mathrm{a}}\right)$ & 2.43 & $\mathrm{dd}(4.4,14.1)$ & 44.3 & $\mathrm{C}^{\prime} 6^{\prime}$ \\
$17^{\prime}\left(\mathrm{H}_{\mathrm{b}}\right)$ & 2.34 & $\mathrm{dd}(8.4,14.0)$ & 44.3 & $\mathrm{C}^{\prime} 6^{\prime}$ \\
$18^{\prime}$ & 3.97 & & 69.5 & \\
$19^{\prime}$ & 1.49 & $\mathrm{~m}$ & 38 & \\
$20^{\prime}\left(\mathrm{H}_{\mathrm{a}}\right)$ & 1.45 & & 26.4 & \\
$20^{\prime}\left(\mathrm{H}_{\mathrm{b}}\right)$ & 1.35 & & 26.4 & \\
$21^{\prime}$ & 1.32 & & 30.2 & \\
$22^{\prime}$ & & & 33.1 & \\
$23^{\prime}$ & 1.29 & & 23.7 & \\
$24^{\prime}$ & 1.32 & $\mathrm{t}(7.1)$ & 14.2 & $\mathrm{C}^{\prime} 4^{\prime}, \mathrm{C}^{\prime}$ \\
$25^{\prime}$ & 0.91 & & & \\
\hline
\end{tabular}




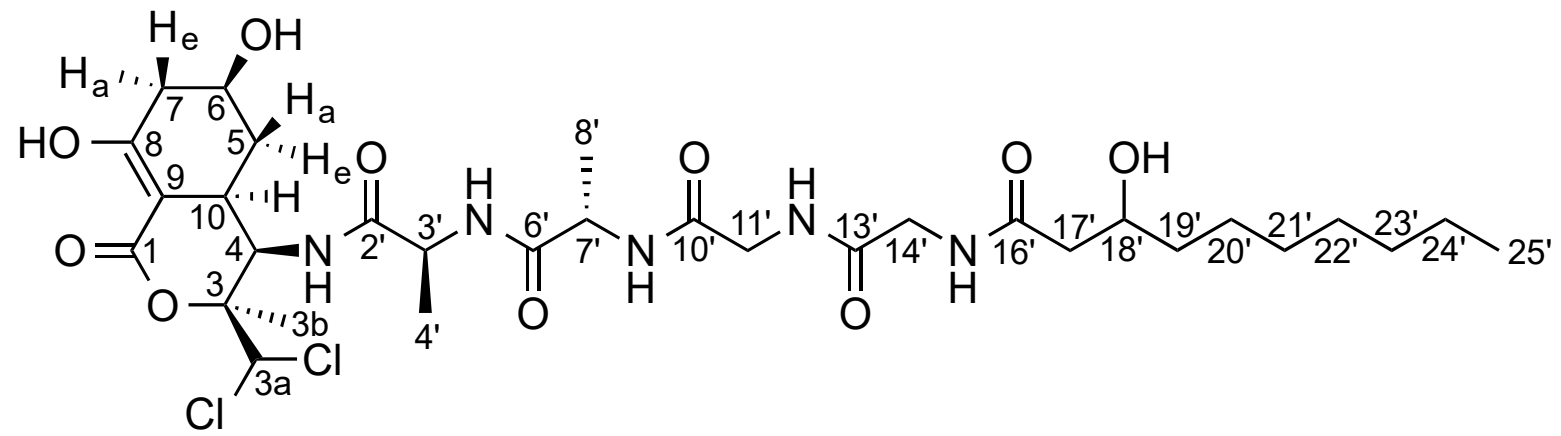

Table S11. NMR spectral data for acybolin E. The structure of acybolin E is shown above.

\begin{tabular}{|c|c|c|c|c|}
\hline $\mathrm{C} / \mathrm{H}$ & $\delta_{H}$ & Multiplicity (Hz) & $\delta_{c}$ & HMBC \\
\hline \multicolumn{5}{|l|}{1} \\
\hline 3 & & & 85.1 & \\
\hline $3 a$ & 6.13 & $s$ & 74.7 & \\
\hline $3 b$ & 1.65 & $\mathrm{~s}$ & 17.8 & $\mathrm{C} 3 \mathrm{a}, \mathrm{C} 4, \mathrm{C} 3$ \\
\hline 4 & 4.61 & $\mathrm{~m}$ & 48.7 & \\
\hline $5\left(\mathrm{H}_{\mathrm{a}}\right)$ & 1.95 & & 34.3 & \\
\hline $5\left(\mathrm{H}_{\mathrm{e}}\right)$ & 1.27 & & 34.3 & C6 \\
\hline 6 & 3.96 & $\mathrm{~m}$ & 64.5 & \\
\hline $7\left(\mathrm{H}_{\mathrm{e}}\right)$ & 2.65 & & 43.9 & $\mathrm{C} 6$ \\
\hline $7\left(\mathrm{H}_{\mathrm{a}}\right)$ & 2.254 & & 43.9 & \\
\hline \multicolumn{5}{|l|}{8} \\
\hline \multicolumn{5}{|l|}{9} \\
\hline 10 & 3.13 & & 32.1 & \\
\hline $2^{\prime}$ & & & 174.2 & \\
\hline $3^{\prime}$ & 4.34 & $q$ & 49.3 & C2', C4' \\
\hline $4^{\prime}$ & 1.37 & & 16.2 & C3' \\
\hline \multicolumn{5}{|l|}{$6^{\prime}$} \\
\hline $7^{\prime}$ & 4.12 & $q$ & 49.9 & C8' \\
\hline $8^{\prime}$ & 1.35 & & 16.2 & $C 7{ }^{\prime}$ \\
\hline $10^{\prime}$ & & & 170.4 & \\
\hline $11^{\prime}\left(\mathrm{H}_{\mathrm{a}}\right)$ & 3.88 & & 42.4 & C10', C13' \\
\hline $11^{\prime}\left(\mathrm{H}_{\mathrm{b}}\right)$ & 3.77 & & & C10' \\
\hline
\end{tabular}


13

$\begin{array}{cc}14^{\prime}\left(H_{\mathrm{a}}\right) & 3.89 \\ 14^{\prime}\left(\mathrm{H}_{\mathrm{b}}\right) & 3.8\end{array}$

$16^{\prime}$

$17^{\prime}\left(\mathrm{H}_{\mathrm{a}}\right)$

$17^{\prime}\left(\mathrm{H}_{\mathrm{b}}\right)$

18' $\quad 3.96$

$19^{\prime} \quad 1.46$

20' $\left(\mathrm{H}_{\mathrm{a}}\right) \quad 1.43$

20' $\left(\mathrm{H}_{\mathrm{b}}\right)$

$21^{\prime}$

22

23' $\quad 1.27$

24' 1.28

$25^{\prime}$

0.88
171.7

42.2

C16', C13'

42.2

173.8

43.2

C18', C16'

43.2

C18', C16', C19'

68.4

36.9

C20'

25.2

25.2

31.7

22.4

C23'

13 
Table S12. HR-ESI-MS data for acybolins A-F and bactobolin I.

\begin{tabular}{ccccc}
\hline Acybolin & {$[\mathbf{M + H}]^{+}$calc } & {$[\mathbf{M + H}]^{+}$obs } & Formula & $\Delta$ ppm \\
\hline A & 736.3091 & 736.3097 & $\mathrm{C}_{32} \mathrm{H}_{52} \mathrm{Cl}_{2} \mathrm{~N}_{5} \mathrm{O}_{10}$ & 0.8 \\
B & 752.3040 & 752.3030 & $\mathrm{C}_{32} \mathrm{H}_{52} \mathrm{Cl}_{2} \mathrm{~N}_{5} \mathrm{O}_{11}$ & 1.3 \\
C & 793.3306 & 793.3287 & $\mathrm{C}_{34} \mathrm{H}_{55} \mathrm{Cl}_{2} \mathrm{~N}_{6} \mathrm{O}_{11}$ & 2.4 \\
D & 722.2935 & 722.2943 & $\mathrm{C}_{31} \mathrm{H}_{49} \mathrm{Cl}_{2} \mathrm{~N}_{5} \mathrm{O}_{10}$ & 1.1 \\
E & 722.2935 & 722.2918 & $\mathrm{C}_{31} \mathrm{H}_{49} \mathrm{Cl}_{2} \mathrm{~N}_{5} \mathrm{O}_{10}$ & 2.4 \\
F & 681.2669 & 681.2678 & $\mathrm{C}_{29} \mathrm{H}_{47} \mathrm{Cl}_{2} \mathrm{~N}_{4} \mathrm{O}_{10}$ & 1.3 \\
G & 738.2884 & 738.2882 & $\mathrm{C}_{31} \mathrm{H}_{50} \mathrm{Cl}_{2} \mathrm{~N}_{5} \mathrm{O}_{11}$ & 0.3 \\
$\mathrm{H}$ & 738.2884 & 738.2885 & $\mathrm{C}_{31} \mathrm{H}_{50} \mathrm{Cl}_{2} \mathrm{~N}_{5} \mathrm{O}_{11}$ & 0.1 \\
I & 809.3255 & 809.3256 & $\mathrm{C}_{34} \mathrm{H}_{55} \mathrm{Cl}_{2} \mathrm{~N}_{6} \mathrm{O}_{12}$ & 0.1 \\
\hline Bactobolin & {$[\mathrm{M+H}]^{+}$calc } & {$[\mathrm{M+H}]^{+}{ }_{\text {obs }}$} & Formula & $\Delta \mathbf{p p m}$ \\
\hline I & 511.1362 & 511.1350 & $\mathrm{C}_{19} \mathrm{H}_{29} \mathrm{Cl}_{2} \mathrm{~N}_{4} \mathrm{O}_{8}$ & 2.3 \\
\hline
\end{tabular}


Table S13. HR-ESI-MS/MS data for acybolins A-I and bactobolin I.

\begin{tabular}{|c|c|c|c|c|}
\hline Acybolin & Ion & {$[\mathrm{M}+\mathrm{H}]_{\text {calc }}^{+}$} & {$[\mathrm{M}+\mathrm{H}]^{+}$obs } & $\Delta p p m$ \\
\hline \multirow[t]{7}{*}{$A$} & b1 & 228.1600 & 228.1597 & 1.3 \\
\hline & y4 & 509.1570 & 509.1562 & 1.6 \\
\hline & b2 & 299.1971 & 299.1970 & 0.4 \\
\hline & y3 & 438.1199 & 438.1196 & 0.7 \\
\hline & b3 & 370.2342 & 370.2339 & 0.8 \\
\hline & y2 & 367.0828 & 367.0825 & 0.8 \\
\hline & y1 & 296.0456 & 296.0453 & 1.0 \\
\hline \multirow[t]{7}{*}{$\mathrm{B}$} & b1 & 228.1600 & 228.1596 & 1.8 \\
\hline & y4 & 525.1519 & 525.1516 & 0.6 \\
\hline & b2 & 299.1971 & 299.1969 & 0.9 \\
\hline & y3 & 454.1148 & 454.1144 & 0.9 \\
\hline & b3 & 370.2342 & 370.2342 & 0.0 \\
\hline & y2 & 383.0777 & 383.0775 & 0.5 \\
\hline & y1 & 312.0406 & 312.0401 & 1.6 \\
\hline \multirow[t]{9}{*}{ C } & b1 & 228.1600 & 228.1589 & 4.8 \\
\hline & y5 & 566.1784 & 566.1768 & 2.8 \\
\hline & b2 & 299.1971 & 299.1960 & 4.8 \\
\hline & y4 & 495.1413 & 495.1398 & 3.0 \\
\hline & b3 & 356.2185 & 356.2178 & 2.0 \\
\hline & y3 & 438.1199 & 438.1187 & 2.7 \\
\hline & b4 & 427.2557 & 427.2548 & 2.1 \\
\hline & y2 & 367.0828 & 367.0815 & 3.5 \\
\hline & y1 & 296.0456 & 296.0442 & 4.7 \\
\hline \multirow[t]{4}{*}{$\mathrm{D}$} & b1 & 228.1600 & 228.1597 & 1.3 \\
\hline & y4 & 495.1413 & 495.1410 & 0.6 \\
\hline & b2 & 299.1971 & 299.1971 & 0.0 \\
\hline & y3 & 424.1042 & 424.1043 & 0.2 \\
\hline
\end{tabular}




\begin{tabular}{|c|c|c|c|c|}
\hline & b3 & 370.2342 & 370.2340 & 0.5 \\
\hline & y2 & 353.0671 & 353.0668 & 0.8 \\
\hline & $\mathrm{y} 1$ & 296.0456 & 296.0455 & 0.3 \\
\hline \multirow[t]{7}{*}{$E$} & b1 & 228.1600 & 228.1591 & 3.9 \\
\hline & y4 & 495.1413 & 495.1401 & 2.4 \\
\hline & b2 & 285.1814 & 285.1806 & 2.8 \\
\hline & y3 & 438.1199 & 438.1183 & 3.7 \\
\hline & b3 & 356.2185 & 356.2176 & 2.5 \\
\hline & y2 & 367.0828 & 367.0821 & 1.9 \\
\hline & $\mathrm{y} 1$ & 296.0456 & 296.0447 & 3.0 \\
\hline \multirow[t]{5}{*}{$F$} & b1 & 228.1600 & 228.1601 & 0.4 \\
\hline & y3 & 454.1148 & 454.1147 & 0.2 \\
\hline & b2 & 299.1971 & 299.1975 & 1.7 \\
\hline & y2 & 383.0777 & 383.0778 & 0.3 \\
\hline & y1 & 312.0406 & 312.0406 & 0.0 \\
\hline \multirow[t]{6}{*}{ G } & b1 & 228.1600 & 228.1599 & 0.4 \\
\hline & y4 & 511.1362 & 511.1363 & 0.2 \\
\hline & $\mathrm{b} 2$ & 299.1971 & 299.1973 & 0.7 \\
\hline & y3 & 440.0991 & 440.0998 & 1.6 \\
\hline & y2 & 369.0620 & 369.0622 & 0.5 \\
\hline & $\mathrm{y} 1$ & 312.0406 & 312.0402 & 1.3 \\
\hline \multirow[t]{7}{*}{$\mathrm{H}$} & b1 & 228.1600 & 228.1598 & 0.9 \\
\hline & y4 & 511.1362 & 511.1364 & 0.4 \\
\hline & b2 & 285.1814 & 285.1816 & 0.7 \\
\hline & y3 & 454.1148 & 454.1153 & 1.1 \\
\hline & b3 & 356.2185 & 356.2186 & 0.3 \\
\hline & y2 & 383.0777 & 383.0774 & 0.8 \\
\hline & $\mathrm{y} 1$ & 312.0406 & 312.0403 & 1.0 \\
\hline \multirow[t]{3}{*}{ I } & b1 & 228.1600 & 228.1596 & 1.8 \\
\hline & y5 & 582.1734 & 582.1732 & 0.3 \\
\hline & b2 & 299.1971 & 299.1969 & 0.7 \\
\hline
\end{tabular}




\begin{tabular}{ccccc} 
& y4 & 511.1362 & 511.1361 & 0.2 \\
b3 & 356.2185 & 356.2186 & 0.3 \\
y3 & 454.1148 & 454.1143 & 1.1 \\
b4 & 427.2557 & 427.2555 & 0.5 \\
\hline \multirow{2}{*}{ Bactobolin } & y2 & 383.0777 & 383.0773 & 1.0 \\
\hline \multirow{2}{*}{ Ion } & m/z (calc) & $\mathrm{m} / \mathbf{z}$ (obs) & $\Delta$ ppm \\
& a2 & 101.0715 & 101.0710 & 5.0 \\
& b2 & 129.0664 & 129.0656 & 6.2 \\
b3 & 200.1035 & 200.1026 & 4.5 \\
& y3 & 454.1148 & 454.1131 & 3.7 \\
y2 & 383.0777 & 383.0767 & 2.6 \\
y1 & 312.0406 & 312.0396 & 3.2 \\
\hline
\end{tabular}


Table S14. Primers for constructing $\Delta b t a Q$ deletion mutant

\begin{tabular}{c|ll}
\hline$\#$ & Primer name & Primer sequence \\
\hline 1 & BTH1239_UpF_HindIII & 5'-ATCTATAAGCTTGTCGCGCTGACGGCGTCG-3' \\
2 & BTH1239_UpR & 5'-TAACGGGGATGCTGGTCATGGCTTCTCTCCAGAACCGCGGC \\
& CATCCGGTCACCGCGCGC-3' \\
3 & BTH1239_DnF & 5'-CTGCGTCGACATTCCGTTGCGCGCGCGGTGACCGGATGGCC \\
& & GCGGTTCTGGAGAGAAGC-3' \\
4 & BTH1239_DnR_KpnI & 5'-ATCTATGGTACCCATGTCCATCGAGAGCTGGCCG-3' \\
5 & BTH1239Tmp_Test_UpF & 5'-CGCATACGACACGAGCGCGC-3' \\
6 & BTH1239Tmp_Test_UpR & 5'-GCAGATGCCGCTTCCACGCG-3' \\
7 & BTH1239Tmp_Test_DnF & 5'-ATGGCACAGGAGCCGTGGCTC-3' \\
8 & BTH1239Tmp_Test_DnR & 5'-CGACGAGGAACTGCGATACGCC-3' \\
\hline
\end{tabular}




\section{SI References}

1) Chandler, J.R., Duerkop, B.A., Hinz, A., West, T.E., Herman, J. P., Churchill, M.E.A., Skerrett, S.J., and Greenberg, E.P. (2009) Mutational analysis of Burkholderia thailandensis quorum sensing and self-aggregation. J. Bacteriol. 191, 5901-5909.

2) Gallagher, L.A., Ramage, E., Patrapuvich, R., Weiss, E.; Brittnacher, M., and Manoil, C. (2013) Sequence-defined transposon mutant library of Burkholderia thailandensis. MBio. 4, e00604-13.

3) Watrous, J., Roach, P., Alexandrov, T., Heath, B.S., Yang, J.Y., Kersten, R.D., van der Voort, M., Pogliano, K., Gross, H., Raaijmakers, J.M., Moore, B.S., Laskin, J., Bandeira, N., Dorrestein, P.C. (2012) Mass spectral molecular networking of living microbial colonies. Prof. Natl. Acad. Sci. USA 109, E1743-E1752.

4) Güntert $P$, Mumenthaler, C. Wüthrich, K. (1997) Torsion angle dynamics for NMR structure calculation with the new program DYANA. J. Mol. Biol. 273, 283-298.

5) Marfey, P. (1984) Determination of D-amino acids. II. Use of a bifunctional reagent, 1,5difluoro-2,4dinitrobenzene. Carlsberg Res. Commun. 49, 591-596.

6) Carr, G., Seyedsayamdost, M.R., Chandler, J.R., Greenberg, E.P., and Clardy, J. (2011) Sources of diversity in bactobolin biosynthesis by Burkholderia thailandensis E264. Org. Lett. 13, 3048-3051.

7) Hoye, T.R., Jeffrey, C.S., and Shao, F. (2007) Mosher ester analysis for the determination of absolute configuration of stereogenic (chiral) carbinol carbons. Nat. Protocol. 2, 24512458.

8) Barrett, A.R., Kang, Y., Inamasu, K.S., Son, M.S., Vukovich, J.M., and Hoang, T.T. (2008) Genetic tools for allelic replacement of Burkholderia species. Appl. Environ. Microbiol. 74, 4498-4508.

9) Blodgett, J.A.V., Oh, D.-C., Cao, S., Currie, C.R., Kolter, R., and Clardy J. Common biosynthetic origins for polycyclic tetramate macrolactams from phylogenetically diverse bacteria. Proc. Natl. Acad. Sci. USA 107, 11692-11697.

10) Majerczyk, C.D., Brittnacher, M., Jacobs, M., Armour, C.D., Radey, M., Schneider, E., Phattarasokul, S., Bunt, R., and Greenberg, E.P. (2014) Global analysis of the Burkholderia thailandensis quorum sensing-controlled regulon. J. Bacteriol. 196, 1412-1424.

11) Lepine, F., Milot, S., Deziel, E., He, J., Rahme, L.G. (2004) Electrospray/mass spectrometric identification and analysis of 4-hydroxy-2-alkylquinolines (HAQs) produced by Pseudomonas aeruginosa. J. Am. Soc. Mass Spectrom. 15, 862-869. 